\title{
CONSERVAÇÃO DE SEMENTES DE Coffea arabica L.: INTERFERÊNCIAS DO GRAU DE UMIDADE E DA TEMPERATURA
}

\section{DANIEL FELIPE DE OLIVEIRA GENTIL}

\author{
Engenheiro Agrônomo
}

Orientador: Prof. Dr. WALTER RODRIGUES DA SILVA

Dissertação apresentada à Escola Superior de Agricultura "Luiz de Queiroz", Universidade de São Paulo, para obtenção do título de Mestre em Agronomia, Área de Concentração: Fitotecnia.

\author{
P I R A C I C A B A \\ Estado de São Paulo - Brasil
}

Novembro - 1999 
Dados Internacionais de Catalogação na Publicação (CIP) DIVISÃo DE BIBLIOTECA E DOCUMENTAÇÃO - Campus "Luiz de Queiroz"/USP

Gentil, Daniel Felipe de Oliveira

Conservação de sementes de Coffea arabica L.: interferências do grau de umidade e da temperatura / Daniel Felipe de Oliveira Gentil. - - Piracicaba, 1999.

$41 \mathrm{p}$.

Dissertação (mestrado) - - Escola Superior de Agricultura Luiz de Queiroz, 1999. Bibliografia.

1. Armazenamento agricola 2. Café 3. Conservação 4. Efeito da temperatura 5. Fisiologia vegetal 6. Qualidade da semente 7. Semente 8. Umidade I. Título

CDD 633.73

QPermifida a copia total ou parcial deste docamento, desde que citada a fonte 0 Autor" 


\section{AGRADECIMENTOS}

A Deus, por tudo.

A Pedro F. Gentil e Maria Marly O. Gentil (in memoriam), pelo amor e dedicação.

A Edna B.M. de Brito e Sérgio I.G. Braga, pela amizade e estímulo.

A Terezinha P. Fraxe, Jaiza M.P. Fraxe, Walber C. Silva, Angela M. Ymakawa, Lucilane D. Sardinha e Maria Lúcia Montes, pelo apoio no momento decisivo de minha carreira profissional.

Aos Pesquisadores do Instituto Nacional de Pesquisas da Amazônia Vânia P. Varela, Sidney A.N. Ferreira e Isolde K. Ferraz, pela iniciação nas pesquisas científicas com sementes.

À Escola Superior de Agricultura "Luiz de Queiroz" (ESALQ), através da Coordenação de Pós-graduação em Fitotecnia, pela oportunidade de realização do Curso de Mestrado.

À Coordenação de Aperfeiçoamento do Pessoal de Ensino Superior, pela concessão da Bolsa de Mestrado.

Ao Professor Walter R. da Silva, por sua orientação, amizade e estímulo durante a realização do Curso e deste trabalho.

Aos Docentes do Departamento de Produção Vegetal da ESALQ, em especial aos Professores Júlio Marcos Filho e Ana D.L.C. Novembre, pelos ensinamentos.

Ao Professor José Laércio Favarin (ESALQ), Pesquisadora Maria Cristina L.L. Dias (Instituto Agronômico do Paraná), Engenheiras Agrônomas Helena M.C.P. Chamma e Maria Heloísa D. Moraes (ESALQ), pelo auxílio técnico na realização do experimento.

Às Estagiárias Renata R. de Almeida e, especialmente, Denise M. de Miranda, pelo auxílio na condução do experimento.

Ao Engenheiro Agrônomo João C.P. Romero (Fazenda Cafés Especiais de Montanha), pelo fornecimento das sementes utilizadas neste trabalho.

Ao senhor Tereziano A. da Silva (Limer Plastic), pelo fornecimento das embalagens usadas neste trabalho. 
Aos Funcionários Marcelo B. Valente, Osmair R. Neves, Ilze H.C.G. das Neves, Maria Ivete M. de Almeida, Roseneide dos Santos, Sônia R.I. dos Santos, João B. Bigelli, Carlos A. Carlet e João E. Jabur Filho, pelo apoio oferecido.

Aos colegas e amigos do Curso de Pós-Graduação em Fitotecnia, em especial Angélica B. Rodo, Leila Martins, Maria Cristina M. Spinola, Maristela Panobianco, Sílvia R.S. de Oliveira e Salvador B. Torres, pela colaboração e atenção em todos os momentos. 


\section{SUMÁRIO}

Página

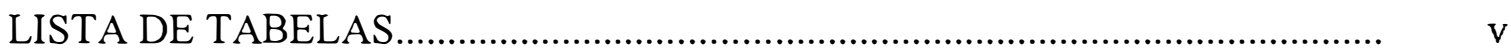

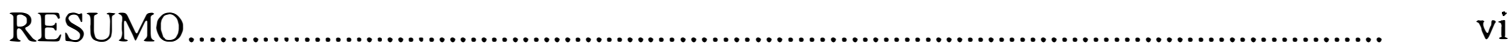

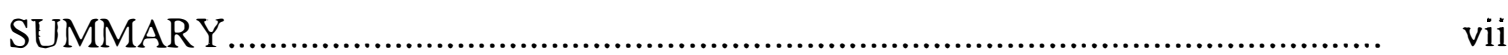

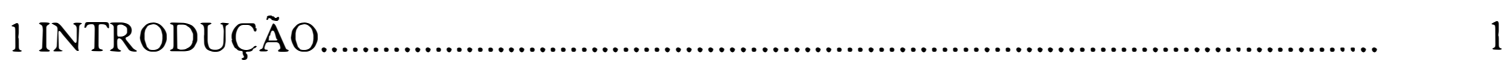

2 REVISÃO DE LITERATURA....................................................................

3 MATERIAL E MÉTODOS.......................................................................... 11

3.1 Preparo das sementes................................................................................ 11

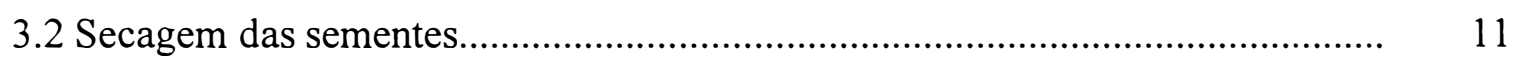

3.3 Armazenamento das sementes..................................................................... 12

3.4 Avaliações da qualidade das sementes.............................................................. 12

3.4.1 Grau de umidade das sementes.................................................................. 12

3.4.2 Teste de germinação........................................................................................ 13

3.4.3 Comprimento de plântula............................................................................ 13

3.4.4 Matéria seca de plântula................................................................................ 13

3.4.5 Velocidade de emergência de plântulas............................................................ 13

3.4.6 Emergência de plântulas................................................................................. 14

3.4.7 Teste de sanidade das sementes.................................................................. 14

3.5 Análise estatística....................................................................................... 14

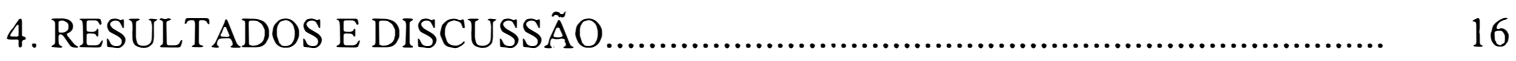

4.1 Caracterização dos tratamentos (graus de umidade)........................................... 16

4.2 Grau de umidade das sementes durante o armazenamento................................ 17

4.3 Germinação das sementes durante o armazenamento......................................... 19

4.4 Vigor das sementes durante o armazenamento................................................... 22

4.5 Sanidade das sementes durante o armazenamento........................................... 28

4.6 Considerações adicionais................................................................................ 29

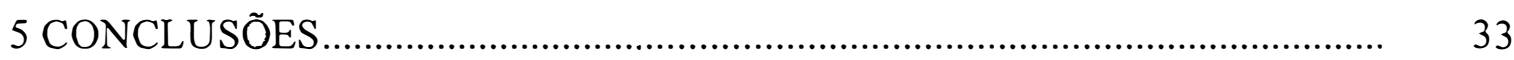

REFERÊNCIAS BIBLIOGRÁFICAS............................................................. 34 


\section{LISTA DE TABELAS}

Página

1 Esquema da análise de variância para as avaliações realizadas no início do armazenamento.

2 Esquema da análise de variância para as avaliações realizadas em cada um dos períodos de armazenamento.

3 Grau de umidade (U), germinação $(\mathrm{G})$, comprimento de plântula (CP), matéria seca de plântula (MSP), índice de velocidade de emergência (IVE) e emergência (E) de plântulas de Coffea arabica cv. Catuaí Amarelo: valores médios ${ }^{1}$ obtidos no início do armazenamento

4 Grau de umidade de sementes de Coffea arabica cv. Catuaí Amarelo: valores médios $(\%, \mathrm{Bu})$ obtidos durante o armazenamento.

5 Germinação de sementes de Coffea arabica cv. Catuaí Amarelo: valores médios (\%) obtidos durante o armazenamento

6 Comprimento de plântula de Coffea arabica cv. Catuaí Amarelo: valores médios $(\mathrm{mm})$ obtidos durante o armazenamento.

7 Matéria seca de plântula de Coffea arabica cv. Catuaí Amarelo: valores

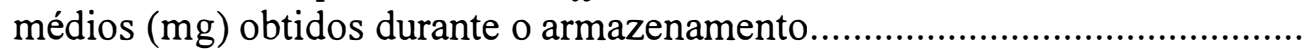

8 Índice de velocidade de emergência de plântulas de Coffea arabica cv. Catuaí Amarelo: valores médios obtidos durante o armazenamento.

9 Emergência de plântulas de Coffea arabica cv. Catuaí Amarelo: valores médios (\%) obtidos durante o armazenamento.

10 Incidência de Penicillium sp. em sementes de Coffea arabica cv. Catuaí Amarelo: valores médios (\%) obtidos durante o armazenamento.

11 Incidência de Aspergillus sp. em sementes de Coffea arabica cv. Catuaí Amarelo: valores médios (\%) obtidos durante o armazenamento. 


\title{
CONSERVAÇÃO DE SEMENTES DE Coffea arabica L.: INTERFERÊNCIAS DO GRAU DE UMIDADE E DA TEMPERATURA
}

\author{
Autor: DANIEL FELIPE DE OLIVEIRA GENTIL \\ Orientador: Prof. Dr. WALTER RODRIGUES DA SILVA
}

\section{RESUMO}

O presente trabalho foi realizado com o objetivo de verificar as influências do grau de umidade e da temperatura de armazenamento na manutenção da qualidade de sementes de Coffea arabica. Desse modo, sementes com 51, 41, 34, 23, 16 e $10 \% \mathrm{H}_{2} \mathrm{O}$, mantidas sob temperaturas de $30^{\circ} \mathrm{C}, 20^{\circ} \mathrm{C}$ e $10^{\circ} \mathrm{C}$ por diferentes periodos de armazenamento, foram submetidas a avaliações periódicas do grau de umidade, da germinação, do vigor e da sanidade. Foi constatado que as reduções do grau de umidade e da temperatura são favoráveis à manutenção da qualidade fisiológica das sementes. As umidades próximas de $23 \%$ beneficiam o estabelecimento de Penicillium sp. e de Aspergillus sp. nas sementes. 


\title{
CONSERVATION OF SEEDS OF Coffea arabica L.: INTERFERENCE OF MOISTURE CONTENT AND TEMPERATURE
}

\author{
Author: DANIEL FELIPE DE OLIVEIRA GENTIL \\ Adviser: Prof. Dr. WALTER RODRIGUES DA SILVA
}

\section{SUMMARY}

The aim of this work was to verify the influences of the moisture content and storage temperature in quality-keeping of Coffea arabica seeds. Thus, 51, 41, 34, 23,16 and $10 \% \mathrm{H}_{2} \mathrm{O}$ seeds kept at temperatures $30^{\circ} \mathrm{C}, 20^{\circ} \mathrm{C}$ and $10^{\circ} \mathrm{C}$ for different storage periods were submitted to periodic evaluations of moisture content, germination, vigour and sanity. Decreases in moisture content and temperature were verified to be favorable to the maintenance of the physiological quality of the seeds. Moisture nearing $23 \%$ benefits the establishment of Penicillium sp. and Aspergillus sp. in seeds. 


\section{INTRODUÇÃO}

O café, produto agrícola importante na economia mundial, movimenta cerca de US\$ 30 bilhões anuais em negócios, quando considerada toda a cadeia produtiva. Representa de 3 a $6 \%$ das receitas cambiais obtidas pelo Brasil e acima de 60\% das exportações efetuadas por Uganda, Burundi, Etiópia e Ruanda (Vegro et al., 1997; Brasil ${ }^{1}$ ). É produzido em 60 países, dentre os quais o Brasil e a Colômbia respondem por mais de $30 \%$ da produção mundial (Fao, 1997; Usda ${ }^{2}$ ). No Brasil, cerca de $80 \%$ da produção corresponde a café arábica oriundo, principalmente, dos Estados de Minas Gerais, São Paulo e Paraná (Matiello, 1991; Usda²).

A espécie Coffea arabica é tradicionalmente propagada por via sexuada (Matiello, 1991; Ascanio, 1994; Costa, 1994), apesar da curta longevidade das sementes e decorrentes dificuldades de sua utilização a longo prazo (Harrington, 1972; Toledo \& Marcos Filho, 1977). Essa limitação imposta ao período de semeadura pode, eventualmente, concentrar a oferta de mudas em épocas nem sempre adequadas ao plantio. Além disso, a ocorrência de adversidades ambientais entre a formação e a colheita dos frutos, tais como geadas, estiagens e problemas fitossanitários, podem provocar a diminuição na oferta de mudas em virtude das dificuldades de manutenção de estoques reguladores de sementes (Silva \& Dias, 1985). A curta longevidade das sementes representa, ainda, um problema desestabilizador dos bancos de sementes em programas de conservação de germoplasma.

A preocupação com a viabilidade das sementes de C. arabica remonta aos primórdios do cultivo da espécie. Alguns relatos apresentam informações de métodos empíricos voltados ao controle do poder germinativo das sementes: Thorn (1998)

\footnotetext{
${ }^{\mathrm{l}}$ http://www.mdic.gov.br.

${ }^{2}$ http://www.fas.usda.gov.
} 
comentou que a espécie pode ter sido introduzida na Arábia (atual lêmen) por escravos sudaneses que, na passagem pela Abissínia (atual Etiópia), coletaram frutos e não extraíram as sementes, o que assegurou a preservação da viabilidade durante a viagem. $\mathrm{Na}$ Arábia, onde surgiram os primeiros plantios da espécie, a exportação de grãos exigia o descascamento dos frutos que, anulando a capacidade germinativa das sementes, garantia a exclusividade do país no fornecimento do produto (Thorn, 1998).

A conservação das sementes em carvão vegetal moído e úmido foi uma prática adotada em diversos países cafeicultores (Bouharmont, 1971). Na atualidade, as sementes são, geralmente, armazenadas com graus de umidade entre 15 e 20\%, acondicionadas em sacaria permeável ao vapor d'água e mantidas em local fresco e arejado (Matiello, 1991); a utilização é possível por quatro a seis meses considerando que, a partir desse período, o poder germinativo declina acentuadamente (Masferré, 1910; McClelland, 1922; Rios, 1929; Haarer, 1962; Koutaka, 1966; Scaranari, 1967; Vossen, 1985; Icea, 1987; Matiello, 1991; Costa, 1994).

Várias pesquisas foram realizadas com a finalidade de estudar a deterioração das sementes de Coffea arabica para permitir a definição de tecnologias capazes de prolongar o período de conservação. Porém, verificam-se controvérsias entre os resultados obtidos, sendo o grau de umidade o ponto principal dessas divergências. Desse modo, o presente trabalho foi realizado com o objetivo de verificar as influências do grau de umidade e temperatura de armazenamento na manutenção da qualidade de sementes de C. arabica. 


\section{REVISÃO DE LITERATURA}

A deterioração em sementes é variável entre as espécies, entre os lotes de sementes da mesma espécie e entre as sementes do mesmo lote (Delouche, 1968). No armazenamento, porém, a velocidade do processo poderá ser controlada em função da longevidade, da qualidade inicial das sementes e das condições do ambiente. Como a longevidade é uma característica genética inerente à espécie, somente a qualidade inicial das sementes e as condições do ambiente de armazenamento podem ser manipuladas (Popinigis, 1977; Toledo \& Marcos Filho, 1977; Carvalho \& Nakagawa, 1988).

A qualidade inicial das sementes de Coffea arabica, admitidas como de curta longevidade (Harrington, 1972; Toledo \& Marcos Filho, 1977), depende dos eventos transcorridos na produção em campo, na colheita e no beneficiamento. Essas etapas, portanto, relacionam-se diretamente com a qualidade fisiológica das sementes obtidas (Moore, 1972; Popinigis, 1977; Carvalho \& Nakagawa, 1988; Romero, 1989).

Durante a maturação das sementes de $C$. arabica, devem ser considerados os fatores desfavoráveis à qualidade fisiológica, como as deficiências minerais e hídricas do solo e as incidências de pragas e doenças (Rodríguez, 1965; Carvalho, 1978; Medina et al., 1982; Rena \& Maestri, 1986; Ascanio, 1994). As adversidades podem impedir que as sementes atinjam a qualidade máxima disponível no potencial genético e, por conseguinte, acelerar a deterioração (Austin, 1972; Harrington, 1972; Popinigis, 1977; Toledo \& Marcos Filho, 1977; Carvalho \& Nakagawa, 1988; Copeland \& McDonald, 1995).

No ponto de maturidade fisiológica das sementes, as transformações degenerativas são reduzidas (Delouche, 1968). Entretanto, as condições adversas ocorridas entre esse estádio e a colheita podem contribuir para aumentar a velocidade da deterioração (Popinigis, 1977). A ocorrência de geada na fase de pré-colheita de frutos 
de Coffea arabica, por exemplo, pode provocar a redução da qualidade físiológica das sementes (Silva \& Dias, 1985).

As sementes de $C$. arabica atingem a maturidade fisiológica entre os estádios de maturação do fruto denominados "verde-cana" e "cereja" (Astolfi et al., 1981; Caixeta, 1981; Herrera et al., 1993; Alizaga \& Herrera, 1995). A colheita, no entanto, é realizada quando os frutos apresentam coloração típica do "cereja", ou seja, vermelha ou amarela conforme a cultivar (Rodríguez, 1965; Carvalho, 1978; Medina et al., 1982; Matiello, 1991; Ascanio, 1994) pois, somente nesse estádio, podem ser descascados mecanicamente de modo adequado (Chin, 1980).

Durante as operações de colheita, descascamento e degomagem dos frutos, os fatores desfavoráveis à qualidade fisiológica das sementes devem ser controlados. Em estudos, realizados por Prado Filho et al. (1984) e Dias \& Barros (1993a), foi evidenciado que os métodos mais empregados na degomagem dos frutos (fermentação natural por 24 e 48 horas e imersão em solução de $\mathrm{NaOH}$ a $0.5 \%$, por um minuto) não prejudicam a qualidade fisiológica das sementes, quando tecnicamente executados.

As sementes de Coffea arabica degomadas apresentam graus de umidade entre 50 e 52\% (Arcila-Pulgarín, 1976; Alizaga \& Herrera, 1995). Caso não haja necessidade de armazenamento, podem ser imediatamente semeadas; em caso contrário, devem ser submetidas à secagem para evitar prejuízos à qualidade físiológica (Miglioranza, 1982; Silva \& Dias, 1985).

A secagem à sombra é prática tradicional na preparação das sementes de C. arabica (Hernandez, 1909; McClelland, 1922; Rios, 1929; Castro, 1960; Rodríguez, 1965; Carvalho, 1978) que, muitas vezes, pode incluir exposição inicial e breve ao sol, visando a redução da umidade excessiva (Bacchi, 1955; Macedo, 1957; Medina et al., 1982; Matiello, 1991). No entanto, a secagem pode ser realizada totalmente ao sol, sem danos ao poder germinativo (Masferré, 1910; Brickwood, 1914; Bacchi, 1955 e 1956), desde que as sementes sejam protegidas nas horas de maior insolação (Castro, 1960; Matiello, 1991). A secagem natural, porém, apresenta o inconveniente da dependência das condições climáticas que, variando com a região e a época do ano, dificultam o 
estabelecimento de recomendações técnicas generalizadas para macrorregiões.

Diante das limitações da secagem natural, alguns pesquisadores passaram a estudar métodos artificiais, pretendendo aperfeiçoar e acelerar o processo de secagem, sem prejudicar a qualidade fisiológica das sementes; assim, Bacchi (1955), ArcilaPulgarín (1976) e Araújo et al. (1989) verificaram que temperaturas de secagem de até $45^{\circ} \mathrm{C}$ não foram desfavoráveis ao poder germinativo. Por outro lado, além dos efeitos imediatos da secagem sobre a qualidade fisiológica, podem ocorrer efeitos latentes, os quais tornam-se aparentes após períodos variáveis de armazenamento (Popinigis, 1977). Até o momento, contudo, os resultados de pesquisas realizadas indicaram que, provavelmente, a qualidade fisiológica das sementes durante o armazenamento seja mais afetada pelo grau de umidade do que pelos métodos de secagem a que foram submetidas (Araújo et al., 1989; Barboza \& Herrera, 1990; Vasconcelos et al., 1992).

$\mathrm{O}$ armazenamento de sementes depende do grau de umidade e de dois fatores ambientais principais: a temperatura e o oxigênio. Em geral, a conservação é conseguida pela redução da atividade metabólica das sementes, através da diminuição do grau de umidade e manutenção de baixas umidade relativa, temperatura e concentração de oxigênio do ambiente (Roberts, 1972). A capacidade das sementes em tolerar a dessecação, entretanto, é variável entre as espécies: a maioria possui sementes que toleram dessecação a graus de umidade próximos de $5 \%$, sendo denominadas "ortodoxas"; outras possuem sementes classificadas como "intermediárias" que, tolerando dessecação a graus de umidade em torno de 10 a $12.5 \%$, têm a viabilidade reduzida em graus de umidade inferiores; outro grupo de espécies possui sementes, conhecidas como "recalcitrantes", que não toleram dessecação a graus de umidade entre 15 e 20\% (Roberts, 1973; Ellis et al., 1990; Hong \& Ellis, 1996). Essa classificação, baseada fundamentalmente na resposta das sementes à dessecação (King \& Roberts, 1979), pode ser auxiliada por outras características fisiológicas e ecológicas das espécies (Roberts \& King, 1980).

O primeiro procedimento para determinar o comportamento de sementes no armazenamento é verificar sua tolerância ou sensibilidade à dessecação (Hong \& Ellis, 1996). No caso de Coffea arabica, foi observado que as sementes toleram 
dessecação até $10 \% \mathrm{H}_{2} \mathrm{O}$ (menor grau de umidade de segurança), sem prejuízos à viabilidade; o grau crítico de umidade está situado entre 5.6 e 10\%, onde verifica-se o início da redução da viabilidade; a dessecação a 4\% $\mathrm{H}_{2} \mathrm{O}$ (grau de umidade letal), anula a viabilidade das sementes (Bacchi, 1955 e 1956; Ellis et al., 1990 e 1991; Hong \& Ellis, 1992; Dussert et al., 1999). Além disso, existem variações no comportamento de diferentes lotes, quanto à ocorrência das injúrias provenientes da dessecação, relacionadas, provavelmente, às condições em que as sementes foram produzidas e processadas (King \& Roberts, 1979 e 1980; Ellis et al., 1990 e 1991; Hong \& Ellis, 1992). Assim, as sementes inicialmente classificadas como recalcitrantes (Roberts, 1973; King \& Roberts, 1979 e 1980), passaram a ser consideradas como de comportamento intermediário aos das categorias ortodoxa e recalcitrante (Aguilera \& Goldbach, 1980; Farrant et al., 1988; Ellis et al., 1990 e 1991; Hong \& Ellis, 1992; Copeland \& McDonald, 1995).

O grau de umidade mais adequado à conservação das sementes de $C$. arabica ainda não foi devidamente definido em virtude das divergências entre os resultados obtidos nas pesquisas: Bacchi (1958), Miglioranza (1982) e Ellis et al. (1990) admitiram como vantajosos graus de umidade baixos, entre 8 e 11\%; outros estudos apresentaram resultados satisfatórios com graus de umidade elevados, entre 30 e $48 \%$ (Valio, 1976; Aguilera \& Goldbach, 1980; Couturon, 1980; Silva \& Dias, 1985; Araújo, 1988; Barboza \& Herrera, 1990; Vasconcelos et al., 1992; Herrera et al., 1993; Alizaga \& Herrera, 1995; Soto et al., 1995); adicionalmente, Vossen (1979) e Miranda (1987) verificaram que graus de umidade intermediários (13 a 35\%) foram desfavoráveis à manutenção da qualidade fisiológica das sementes no armazenamento, muito embora existam resultados opostos (Miranda et al., 1984; Araújo et al., 1989). Consequentemente, as recomendações técnicas difundidas são contraditórias (Storing, 1939; Camargo \& Teles Júnior, 1953; Moraes, 1963; Rodríguez, 1965; Costé, 1968; Carvalho, 1978; Medina et al., 1982; Vossen, 1985; Matiello, 1991; Ascanio, 1994).

$\mathrm{O}$ armazenamento de sementes de Coffea arabica consiste, geralmente, no acondicionamento em embalagem permeável ao vapor d'água, seguido de conservação em local fresco e arejado (Matiello, 1991). Nessas condições, foi verificado 
que a manutenção da viabilidade pode variar de um a nove meses (Bacchi, 1958; Bouharmont, 1971; Vossen, 1979; Couturon, 1980; Miranda, 1987; Araújo, 1988; Araújo et al., 1989; Vasconcelos et al., 1992; Dias \& Barros, 1993b; Soto et al., 1995). Por isso, o prazo recomendado ao armazenamento das sementes varia de quatro a seis meses considerando que, a partir desse período, a viabilidade tende a declinar acentuadamente (Masferré, 1910; McClelland, 1922; Rios, 1929; Haarer, 1962; Moraes, 1963; Koutaka, 1966; Scaranari, 1967; Carvalho, 1978; Vossen, 1985; Icea, 1987; Matiello, 1991; Ascanio, 1994; Costa, 1994).

No armazenamento, a semente e a atmosfera circundante encontram-se em permanente troca hídrica até atingirem o equilibrio higroscópico, quando passam a trocar iguais quantidades de água (Popinigis, 1977; Toledo \& Marcos Filho, 1977). Bacchi (1958) admitiu que o período de conservação das sementes de C. arabica, em ambiente não controlado, seja inversamente proporcional ao grau de umidade inicial e diretamente proporcional à velocidade de dessecação (até ser atingido o equilibrio higroscópico). Entretanto, tais afirmações não foram ratificadas por Miranda (1987) e Vasconcelos et al. (1992) ao observarem que sementes, com diferentes graus de umidade, apresentaram conservação semelhante; da mesma forma, Matiello (1991) considerou que, quanto mais lenta for a retirada de água das sementes, maior será a preservação da viabilidade. Adicionalmente, Araújo (1988) verificou que o armazenamento de sementes, com grau de umidade inicial de $48 \%$ em embalagem permeável ao vapor d'água, foi o único tratamento que manteve taxa elevada de germinação, durante nove meses em ambiente não controlado.

Estudos procuraram determinar as condições de umidade relativa e temperatura do ar que possibilitassem o armazenamento de sementes de Coffea arabica por maior período de tempo. Com esse objetivo, Bendaña (1962) verificou que a viabilidade das sementes, com grau de umidade inicial entre 16 e $17 \%$, foi mantida por seis e doze meses em ambientes com umidades relativas respectivas de 30 e $40 \%$, sob temperatura de $10^{\circ} \mathrm{C}$; em ambiente com umidade relativa de $50 \%$ e temperatura idêntica, a viabilidade foi preservada por 48 meses. Ortuño \& Echandi (1980) e Aguilera $\&$ Goldbach (1980), empregando sementes com grau de umidade inicial de 30 e $43 \%$, 
umidade relativa de $50 \%$ e temperatura de $10^{\circ} \mathrm{C}$, mantiveram a viabilidade por três meses; quando a umidade relativa superou $90 \%$, a conservação da viabilidade das sementes com grau de umidade de $43 \%$ foi ampliada para seis meses (Aguilera \& Goldbach, 1980). Ainda com o mesmo propósito, Couturon (1980) observou que a viabilidade das sementes, com grau de umidade inicial de $40 \%$, foi mantida por 32 meses, em ambiente com umidade relativa de $100 \%$ e temperatura de $19^{\circ} \mathrm{C}$.

Outras pesquisas empregaram o controle exclusivo da temperatura ou da umidade relativa no armazenamento das sementes. Desse modo, em ambiente sem o controle da umidade relativa do ar, Couturon (1980), Miranda et al. (1984) e Dias \& Barros (1993a) constataram que a viabilidade das sementes foi mantida por quatro a seis meses sob temperatura próxima a $20^{\circ} \mathrm{C}$; Vossen (1979) verificou taxas elevadas de germinação por sete e doze meses, sob temperaturas de $10^{\circ} \mathrm{C}$ e $15^{\circ} \mathrm{C}$, respectivamente. Por outro lado, o armazenamento das sementes em atmosfera saturada de umidade, sem o controle da temperatura, possibilitou a manutenção da viabilidade por quatro a quinze meses (Bouharmont, 1971; Couturon, 1980).

A conservação das sementes em carvão vegetal moído foi uma prática utilizada em diversos países cafeicultores. Masferré (1910) mencionou que as sementes podiam ser armazenadas por mais de dois anos quando, misturadas com carvão vegetal moído, eram mantidas em recipientes vedados. Outro método consistia em misturar as sementes com o carvão vegetal moído, dispor o material em camada espessa (cerca de $10 \mathrm{~cm}$ ) coberta com saco de aniagem umedecido e pulverizar água periodicamente; essas condições possibilitavam a preservação da viabilidade por mais de quatro meses, apesar de não impedirem as alterações no grau de umidade (Bouharmont, 1971). Para restringir as variações na umidade, Bouharmont (1971), testando o uso da mistura sob atmosfera saturada de umidade, conseguiu manter a viabilidade das sementes por treze meses de armazenamento.

O emprego de embalagens impermeáveis ao vapor d’água, como recipientes de vidro, latas metálicas, sacos de alumínio ou de polietileno, vem sendo estudado para uso no armazenamento de sementes de $C$. arabica. Essas embalagens, eliminando a influência da umidade relativa do ar externo no ambiente interno, 
dificultam as alterações no grau de umidade das sementes. Assim, os resultados têm evidenciado que nessas embalagens, em ambiente sem o controle da temperatura, os graus de umidade intermediários (13 a $25 \%$ ) foram menos eficientes na manutenção da viabilidade do que os de valores extremos (10 e 40\%) (Bacchi, 1958; Valio, 1976; Vossen, 1979; Silva \& Dias, 1985; Miranda, 1987; Araújo, 1988; Vasconcelos et al., 1992; Dias \& Barros, 1993b; Soto et al., 1995).

Esse comportamento das sementes foi similarmente observado no armazenamento em temperaturas próximas a $20^{\circ} \mathrm{C}$. Miglioranza (1982), Silva \& Dias (1985) e Hong \& Ellis (1992) verificaram que, em sementes com graus de umidade entre 12 e $24 \%$, a taxa de germinação permaneceu elevada por um a quatro meses, enquanto em sementes com graus de umidade de 9 e $35 \%$ o mesmo ocorreu por doze e quatro meses, respectivamente. Mesmo assim, Miranda et al. (1984) observaram que, em sementes com grau de umidade de $16 \%$, a viabilidade foi mantida por oito meses de armazenamento.

Vossen (1979), ao estudar o armazenamento a $15^{\circ} \mathrm{C}$, verificou efeitos adversos de graus de umidade intermediários (13 a 35\%) sobre a viabilidade das sementes de Coffea arabica. Em seu trabalho, somente as sementes com graus de umidade de 11 e $41 \%$ germinaram satisfatoriamente após 24 meses de armazenamento; aos 30 meses, apenas as sementes com grau de umidade de $41 \%$ mantiveram taxa de germinação elevada. De modo aproximado, Barboza \& Herrera (1990), Ellis et al. (1990), Hong \& Ellis (1992), Herrera et al. (1993) e Alizaga \& Herrera (1995) confirmaram os resultados obtidos por Vossen (1979), apesar de Hong \& Ellis (1992) terem verificado que, em sementes com grau de umidade entre 9 e $10 \%$, a viabilidade foi mantida por 36 meses.

O comportamento das sementes no armazenamento a $10^{\circ} \mathrm{C}$, em embalagens impermeáveis, não parece devidamente esclarecido pelas pesquisas realizadas (Vossen, 1979; Aguilera \& Goldbach, 1980; Barboza \& Herrera, 1990; Hong \& Ellis, 1992); os resultados mais favoráveis à conservação foram obtidos em sementes com graus de umidade entre 8 e 10\% (Hong \& Ellis, 1992) e de 48\% (Vossen, 1979). Com relação às temperaturas abaixo de $10^{\circ} \mathrm{C}$, alguns estudos indicaram que essas 
condições, provavelmente, não sejam as mais adequadas ao armazenamento das sementes (Bouharmont, 1971; Vossen, 1979; Aguilera \& Goldbach, 1980; Couturon, 1980; Miranda et al., 1984; Araújo, 1988; Ellis et al., 1990; Hong \& Ellis, 1992; Alizaga \& Herrera, 1995).

A ocorrência de microrganismos pode representar um evento significativo durante o armazenamento de sementes de C. arabica, principalmente quando utilizadas embalagens impermeáveis ao vapor d'água e sementes com elevados graus de umidade (Miranda et al., 1984). Algumas incidências de microrganismos de campo, como Fusarium sp., Cladosporium sp. e Phoma sp., verificadas por Miranda (1987) e Dias \& Barros (1993a e b), não causaram prejuízos à qualidade fisiológica das sementes. Por outro lado, dentre os microrganismos de armazenamento, foram identificados os fungos Penicillium sp. e Aspergillus sp. (Miranda, 1987; Dias \& Barros, 1993a e b), cujo controle pode ser alcançado através do tratamento químico (Filani, 1972; Miranda et al., 1984; Miranda, 1987).

Os conhecimentos sobre a conservação de sementes de Coffea arabica, como pode ser evidenciado, não são conclusivos. Quando comparados entre si, os trabalhos realizados indicam resultados discordantes, principalmente em relação ao grau de umidade das sementes. Paralelamente, o entendimento da interferência das causas de variação é, frequentemente, dificultado pelo excessivo número de fatores analisados conjuntamente em um mesmo experimento. Além disso, a expressiva variabilidade entre as metodologias adotadas prejudica as comparações entre resultados oriundos de diferentes ensaios. 


\section{MATERIAL E MÉTODOS}

O experimento foi conduzido nos Laboratórios de Análise de Sementes/Departamento de Produção Vegetal e de Patologia de Sementes/Departamento de Entomologia, Fitopatologia e Zoologia Agrícola, pertencentes à Escola Superior de Agricultura "Luiz de Queiroz"/Universidade de São Paulo, em Piracicaba/SP.

Foram utilizados frutos de Coffea arabica L. cv. Catuaí Amarelo, linhagem H 2077-2-5-86, colhidos no estádio "cereja" na Fazenda Cafés Especiais de Montanha (Ouro Fino/MG).

\subsection{Preparo das sementes}

Os frutos foram descascados mecanicamente e, em seguida, degomados quimicamente através da imersão em solução de hidróxido de sódio a $0.5 \%$, por um minuto, com posterior lavagem em água corrente durante cinco minutos (Dias \& Barros, 1993a). Posteriormente, foi realizada catação manual para a eliminação de frutos inteiros, restos de epicarpo (cascas), sementes sem endocarpo (pergaminho) e outras impurezas presentes no lote.

\subsection{Secagem das sementes}

Primeiramente, foi retirada uma amostra de sementes para a verificação do grau de umidade inicial do lote. Após essa determinação, foi coletado o material constituinte do tratamento denominado $51 \% \mathrm{H}_{2} \mathrm{O}$; as sementes restantes foram submetidas à secagem, em estufa com circulação de ar constante a $30 \pm 3^{\circ} \mathrm{C}$, para a obtenção dos demais tratamentos $\left(41,34,23,16\right.$ e $\left.10 \% \mathrm{H}_{2} \mathrm{O}\right)$ referentes aos graus de umidade desejados.

Os tratamentos foram obtidos através do acompanhamento da perda de 
peso de sementes durante a secagem. Para tanto, amostras de sementes, com pesos iniciais previamente conhecidos, foram acondicionadas em sacos de filó e distribuídas nas bandejas da estufa para pesagens a intervalos regulares. Os pesos finais das amostras, correspondentes a cada um dos graus de umidade desejados, foram previamente conhecidos através da equação descrita por Cromarty et al. (1985):

$$
\begin{aligned}
& \mathrm{Pf}=\mathrm{Pi}(100-\mathrm{Ui}) \times(100-\mathrm{Uf})^{-1} \text {, onde: } \\
& \mathrm{Pf}=\text { peso da amostra }(\mathrm{g}) \text { após a secagem; } \\
& \mathrm{Pi}=\text { peso da amostra }(\mathrm{g}) \text { antes da secagem; } \\
& \mathrm{Ui}=\text { grau de umidade }(\%) \text { antes da secagem; } \\
& \mathrm{Uf}=\text { grau de umidade }(\%) \text { desejado após a secagem. }
\end{aligned}
$$

À medida que o lote foi atingindo graus de umidade próximos aos desejados, amostras foram retiradas, homogeneizadas e divididas em frações que, por sua vez, foram embaladas em sacos de polietileno $(0.14 \mathrm{~mm}$ de espessura) e mantidas, provisoriamente, em ambiente a $20 \pm 2{ }^{\circ} \mathrm{C}$, durante a obtenção de todos os tratamentos.

\subsection{Armazenamento das sementes}

As amostras, correspondentes aos diferentes graus de umidade, foram distribuídas em ambientes com temperatura controlada de $10 \pm 1^{\circ} \mathrm{C}, 20 \pm 2^{\circ} \mathrm{C}$ e $30 \pm$ $2^{\circ} \mathrm{C}$. No início do armazenamento (caracterização dos tratamentos graus de umidade) e após $5,10,15,20,25,29,34,38,43$ e 48 semanas, as sementes foram submetidas às avaliações da qualidade.

\subsection{Avaliações da qualidade das sementes}

3.4.1. Grau de umidade das sementes: foi determinado através do método de estufa a $105 \pm 3^{\circ} \mathrm{C} / 24$ horas (Brasil, 1992). Os resultados, expressos em percentagem, foram calculados com base no peso úmido $(\mathrm{Bu})$. 
3.4.2. Teste de germinação: foi realizado em germinador a $30^{\circ} \mathrm{C}$ com o substrato papel toalha, na forma de rolo, umedecido em volume de água equivalente a 2.5 vezes o seu peso sem hidratação. Foram empregadas 50 sementes/repetição com os pergaminhos retirados manualmente antes de sua distribuição no substrato. As contagens, realizadas aos 15 e 30 dias após a instalação do teste, constituíram os resultados expressos em percentagem de plântulas normais (Brasil, 1992).

3.4.3. Comprimento de plântula: foram seguidos os procedimentos de instalação adotados no teste de germinação, empregando 15 sementes/repetição distribuídas sobre linha traçada a $10 \mathrm{~cm}$ da extremidade superior do substrato. Aos 30 dias após a instalação do teste, foi realizada a medição da distância entre a extremidade da raiz primária e a região de inserção das folhas cotiledonares. O comprimento $(\mathrm{mm})$ médio de plântula foi obtido através da divisão do somatório das medidas registradas pelo número de sementes utilizadas (quinze).

3.4.4. Matéria seca de plântula: após a obtenção dos dados de comprimento, as plântulas tiveram os eixos hipocótilo-raiz isolados, acondicionados em saco de papel e colocados em estufa a $80^{\circ} \mathrm{C} / 24$ horas, previamente às pesagens (Marcos Filho et al., 1987). O peso (mg) médio da matéria seca de plântula foi obtido através da divisão do peso total registrado pelo número de sementes empregadas (quinze).

3.4.5. Velocidade de emergência de plântulas: foi realizada em caixas plásticas contendo areia peneirada, utilizando 50 sementes/repetição dispostas a $2 \mathrm{~cm}$ de profundidade no substrato. A irrigação, realizada sempre que necessário, procurou manter o substrato úmido.

$\mathrm{Na}$ avaliação, realizada a cada três dias entre a instalação do teste e o encerramento da emergência na população, foram consideradas como emersas as plântulas que atingiram o estádio "palito de fósforo" (Ascanio, 1994). Para o cálculo do Índice de Velocidade de Emergência (IVE) foi empregada a equação proposta por Maguire (1962): 


$$
\mathrm{IVE}=\frac{\mathrm{E} 1}{\mathrm{D} 1}+\frac{\mathrm{E} 2}{\mathrm{D} 2}+\ldots \ldots+\frac{\mathrm{En}}{\mathrm{Dn}} \text {, onde: }
$$

$E 1, E 2, \ldots, E n=$ percentagem de plântulas emersas obtidas na primeira, segunda, . . , e última contagens, respectivamente;

$\mathrm{D} 1, \mathrm{D} 2, \ldots, \mathrm{Dn}=$ número de dias decorridos da semeadura à primeira, segunda, . . , e última contagens, respectivamente.

3.4.6. Emergência de plântulas: foi considerado, para o cálculo em percentagem, o total de plântulas emersas na avaliação da velocidade de emergência.

3.4.7. Teste de sanidade das sementes: foram empregadas 50 sementes/repetição distribuídas em placas de Petri (10 sementes/placa) sobre três folhas de papel de filtro umedecidas com água destilada. A incubação foi realizada em câmara a $20 \pm 2{ }^{\circ} \mathrm{C}$, em regime alternado de $12 \mathrm{~h}$ de luz/12 h de escuro, com lâmpada fluorescente durante 7 dias. Após esse período, foi efetuada a avaliação da incidência de Penicillium sp. e Aspergillus sp., com os auxílios de microscópios estereoscópico e composto (Dias \& Barros, 1993a).

\subsection{Análise estatística}

Foi adotado o delineamento experimental inteiramente casualizado, considerando 6 tratamentos (graus de umidade) no início do armazenamento e 18 tratamentos ( 6 graus de umidade $\times 3$ condições térmicas) durante o armazenamento, com 4 repetições. Os dados de germinação e de emergência foram transformados em arco seno da raiz quadrada de $\mathrm{x} / 100$ (Ferreira, 1991).

O esquema da análise de variância dos dados obtidos no início do armazenamento está apresentado na Tabela 1. Para os dados obtidos durante o armazenamento, a análise de variância (Tabela 2) foi conduzida isoladamente em cada época de avaliação. A comparação das médias foi realizada pelo teste de Tukey ao nível 
de $5 \%$ de probabilidade (Zonta \& Machado, 1984).

Os dados de grau de umidade e de sanidade não foram submetidos à análise estatística.

Tabela 1. Esquema da análise de variância para as avaliações realizadas no início do armazenamento.

\begin{tabular}{lc}
\hline CAUSAS DE VARIAÇÁO & GRAUS DE LIBERDADE \\
\hline Tratamentos & 5 \\
Resíduo & 18 \\
\hline Total & 23 \\
\hline
\end{tabular}

Tabela 2. Esquema da análise de variância para as avaliações realizadas em cada um dos períodos de armazenamento.

\begin{tabular}{lc}
\hline CAUSAS DE VARIAÇÃO & GRAUS DE LIBERDADE \\
\hline Tratamentos & 17 \\
Resíduo & 54 \\
\hline Total & 71 \\
\hline
\end{tabular}




\section{RESULTADOS E DISCUSSÃO}

\subsection{Caracterização dos tratamentos (graus de umidade)}

As avaliações realizadas no início do armazenamento (Tabela 3), além de procurar aferir a relação entre os graus de umidade obtidos e os desejados, visaram detectar eventuais efeitos da dessecação sobre a qualidade fisiológica das sementes.

Os resultados de grau de umidade indicaram proximidade entre os valores desejados e os valores experimentalmente atingidos e, dessa maneira, sugeriram a existência de eficiência do método de acompanhamento da secagem adotado para a obtenção dos tratamentos.

Por outro lado, a desejável uniformidade inicial entre os tratamentos, referente à qualidade fisiológica, não foi completamente alcançada. O tratamento de $10 \% \mathrm{H}_{2} \mathrm{O}$ tendeu a demonstrar inferioridade no desempenho em relação aos demais, particularmente nas comparações com o de $34 \% \mathrm{H}_{2} \mathrm{O}$. Além disso, o tratamento de $41 \%$ $\mathrm{H}_{2} \mathrm{O}$ superou o de $16 \% \mathrm{H}_{2} \mathrm{O}$ nos testes de comprimento e de matéria seca de plântula. Apesar de dificultarem as comparações de desempenho durante o armazenamento, essas variações são de atenuação complexa quando a secagem necessita ser aplicada em massas que, quantitativamente, impeçam o controle minucioso do processo de dessecação.

De um modo geral, a dessecação a $10 \% \mathrm{H}_{2} \mathrm{O}$, admitido como o menor grau de umidade de segurança, não tem indicado prejuízos à qualidade fisiológica das sementes (Bacchi, 1955 e 1956; Miranda 1987; Ellis et al., 1990 e 1991; Hong \& Ellis, 1992). Entretanto, podem existir variações na ocorrência de injúrias provenientes da dessecação, relacionadas possivelmente às condições em que as sementes foram produzidas e processadas (King \& Roberts, 1979 e 1980; Ellis et al., 1990 e 1991; Hong 
$\&$ Ellis, 1992). No presente trabalho, pressupondo que os fatores adversos oriundos da produção em campo, colheita, descascamento e degomagem dos frutos tenham sido igualmente distribuídos entre os tratamentos, é provável que o processo de secagem tenha afetado negativamente a qualidade das sementes dessecadas a $16 \% \mathrm{H}_{2} \mathrm{O}$ e, principalmente, a $10 \% \mathrm{H}_{2} \mathrm{O}$; contudo, segundo Araújo et al. (1989), existem dúvidas a respeito das influências da temperatura e da velocidade de secagem sobre a qualidade fisiológica das sementes de Coffea arabica.

Tabela 3. Grau de umidade (U), germinação $(\mathrm{G})$, comprimento de plântula $(\mathrm{CP})$, matéria seca de plântula (MSP), índice de velocidade de emergência (IVE) e emergência (E) de plântulas de Coffea arabica cv. Catuaí Amarelo: valores médios ${ }^{1}$ obtidos no início do armazenamento.

\begin{tabular}{ccccccc}
\hline Tratamentos & $\mathrm{U}(\%, \mathrm{Bu})$ & $\mathrm{G}(\%)$ & $\mathrm{CP}(\mathrm{mm})$ & $\mathrm{MSP}(\mathrm{mg})$ & IVE & $\mathrm{E}(\%)$ \\
\hline $51 \% \mathrm{H}_{2} \mathrm{O}$ & 51.3 & $89 \mathrm{ab}$ & $59.9 \mathrm{bc}$ & $22.5 \mathrm{ab}$ & $1.27 \mathrm{ab}$ & $94 \mathrm{ab}$ \\
$41 \% \mathrm{H}_{2} \mathrm{O}$ & 41.4 & $91 \mathrm{ab}$ & $85.1 \mathrm{ab}$ & $28.0 \mathrm{a}$ & $1.31 \mathrm{a}$ & $98 \mathrm{a}$ \\
$34 \% \mathrm{H}_{2} \mathrm{O}$ & 34.4 & $94 \mathrm{a}$ & $92.4 \mathrm{a}$ & $26.2 \mathrm{ab}$ & $1.31 \mathrm{a}$ & $97 \mathrm{ab}$ \\
$23 \% \mathrm{H}_{2} \mathrm{O}$ & 22.9 & $87 \mathrm{ab}$ & $60.6 \mathrm{bc}$ & $22.0 \mathrm{ab}$ & $1.42 \mathrm{a}$ & $100 \mathrm{a}$ \\
$16 \% \mathrm{H}_{2} \mathrm{O}$ & 16.3 & $90 \mathrm{ab}$ & $49.0 \mathrm{c}$ & $19.5 \mathrm{~b}$ & $1.38 \mathrm{a}$ & $98 \mathrm{a}$ \\
$10 \% \mathrm{H}_{2} \mathrm{O}$ & 10.5 & $83 \mathrm{~b}$ & $60.8 \mathrm{bc}$ & $21.0 \mathrm{ab}$ & $1.10 \mathrm{~b}$ & $85 \mathrm{~b}$
\end{tabular}

1. Médias seguidas de mesma letra na coluna não diferem entre si, pelo teste de Tukey, ao nível de $5 \%$ de probabilidade.

\subsection{Grau de umidade das sementes durante 0 armazenamento}

A determinação do grau de umidade das sementes, ao longo do período experimental (Tabela 4), permitiu observar estabilidade, dentro de cada grau de umidade, representada por desvios inferiores a $0.8 \%$ em relação aos dados obtidos no início do armazenamento (Tabela 3). Dessa forma, a embalagem utilizada demonstrou, independentemente da temperatura considerada, eficiência na manutenção da identidade dos tratamentos relativos aos graus de umidade e, em decorrência, confiabilidade nas comparações realizadas durante o armazenamento. 


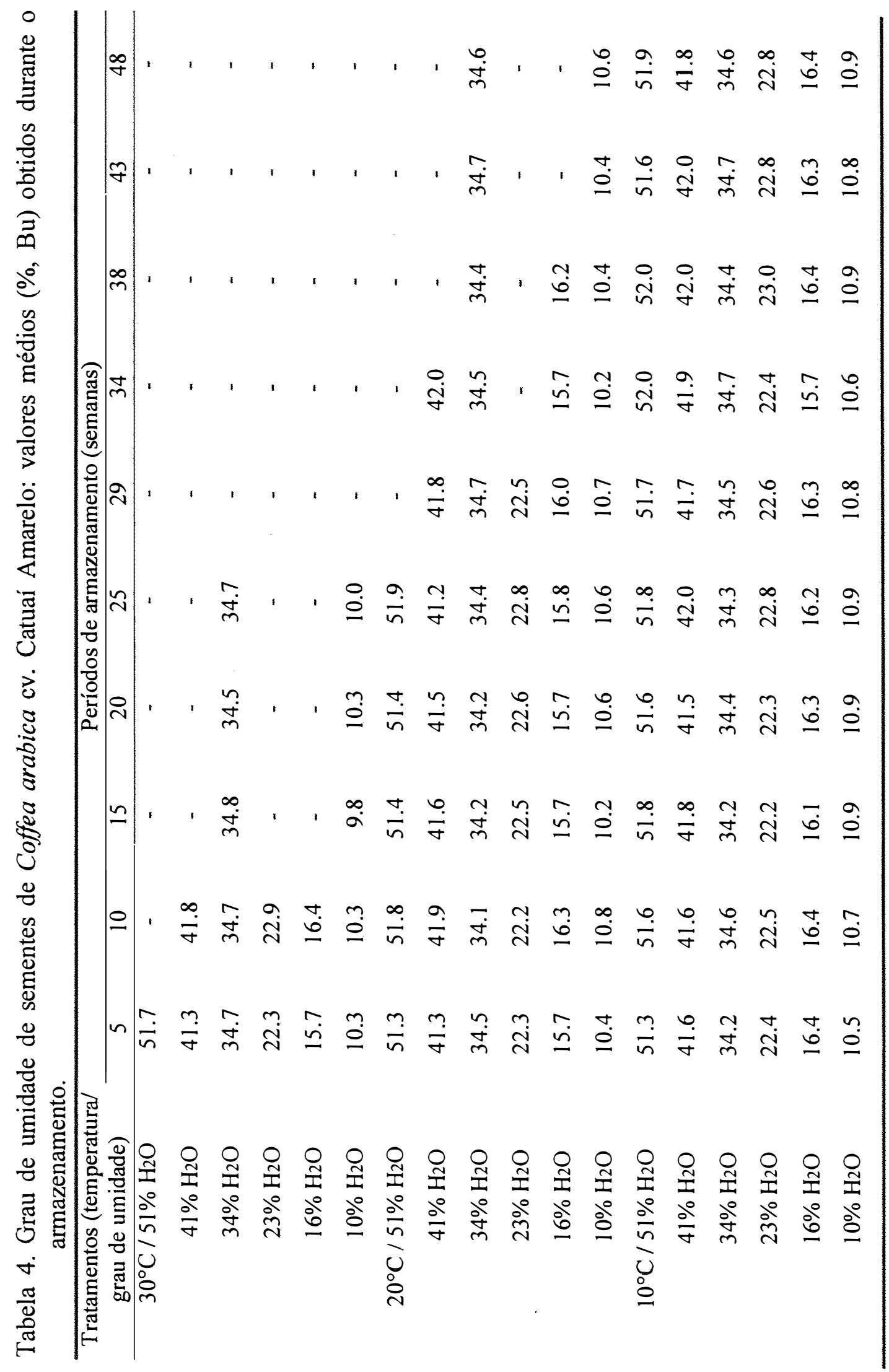




\subsection{Germinação das sementes durante o armazenamento}

Os dados obtidos (Tabela 5) indicaram que a temperatura de $30^{\circ} \mathrm{C}$ foi a que mais evidenciou, em curto período, o declínio da germinação, particularmente nas sementes com graus de umidade de 51, 41, 23 e 16\%; as sementes com 34 e $10 \% \mathrm{H}_{2} \mathrm{O}$, embora apresentando taxas acentuadamente decrescentes de germinação, tiveram a perda do poder germinativo mais retardada e, comparativamente, menos intensa nas sementes com grau de umidade de $10 \%$.

No ambiente a $20^{\circ} \mathrm{C}$, dentro dos intervalos de 51 a $34 \% \mathrm{H}_{2} \mathrm{O}$ e de 23 a $10 \% \mathrm{H}_{2} \mathrm{O}$, a redução do grau de umidade das sementes permitiu que a manutenção do poder germinativo fosse prorrogada e, por conseguinte, as sementes com 34 e $10 \% \mathrm{H}_{2} \mathrm{O}$ apresentassem períodos maiores de conservação. Entretanto, quando comparados entre si, o grau de umidade de $10 \%$ foi mais favorável à conservação das sementes do que o de $34 \% \mathrm{H}_{2} \mathrm{O}$, sugerindo a existência de maior intensidade de deterioração nas sementes que possuíam este grau de umidade, de modo similar ao verificado no ambiente a $30^{\circ} \mathrm{C}$.

Assim, nos ambientes a $30^{\circ} \mathrm{C}$ e a $20^{\circ} \mathrm{C}$, apesar de verificada a superioridade das sementes com $10 \% \mathrm{H}_{2} \mathrm{O}$ nas comparações com as dos demais graus de umidade, foi evidenciada a inferioridade no desempenho, ao longo do armazenamento, das sementes com 51, 41, 23 e 16\% $\mathrm{H}_{2} \mathrm{O}$ em relação as que apresentavam $34 \% \mathrm{H}_{2} \mathrm{O}$. Segundo Ellis et al. (1990), este comportamento, aproximadamente verificado em outros estudos (Vossen, 1979; Miranda, 1987), pode estar relacionado, em parte, com a ativação e a sustentação de mecanismos de reparo em sementes com graus de umidade elevados, tendo como consequência a ampliação do período de conservação (Villiers \& Edgcumbe, 1975; Ibrahim \& Roberts, 1983; Ibrahim et al., 1983; Roberts \& Ellis, 1989; Probert \& Smith, 1996). De qualquer modo, apesar de concordarem parcialmente com essa hipótese, os resultados obtidos sugeriram que a acumulação de danos da deterioração tenha sido menor nas sementes com graus de umidade de 10 e $34 \%$ do que nos demais casos.

No armazenamento a $10^{\circ} \mathrm{C}$, a redução do grau de umidade tendeu a aumentar o período de conservação das sementes. O declínio do poder germinativo foi 
detectado, primeiramente, nas sementes com $51 \% \mathrm{H}_{2} \mathrm{O}$ e, em seguida, nas sementes com 41 e $34 \% \mathrm{H}_{2} \mathrm{O}$. No final do período experimental, foi possível verificar, entre os demais graus de umidade, a superioridade das sementes com 16 e $10 \% \mathrm{H}_{2} \mathrm{O}$ em relação às sementes com $23 \% \mathrm{H}_{2} \mathrm{O}$.

De modo geral, fixados os graus de umidade das sementes, os resultados revelaram que as sementes mantidas a $10^{\circ} \mathrm{C}$, no decorrer do período experimental, foram gradualmente demonstrando sua superioridade em relação às sementes armazenadas a $20^{\circ} \mathrm{C}$ e a $30^{\circ} \mathrm{C}$; a mesma tendência foi observada na germinação das sementes mantidas a $20^{\circ} \mathrm{C}$ em relação às armazenadas a $30^{\circ} \mathrm{C}$. Adicionalmente, levando em conta as variações no grau de umidade, foi observado que as sementes armazenadas a $30^{\circ} \mathrm{C}$ perderam mais rapidamente o poder germinativo, mesmo quando possuíam graus de umidade baixos, enquanto a manutenção do poder germinativo foi mais prolongada, mesmo com graus de umidade elevados, nas sementes armazenadas a $10^{\circ} \mathrm{C}$.

Dessa maneira, o conjunto dos dados obtidos evidenciou que, independentemente do grau de umidade considerado, a redução da temperatura de armazenamento tendeu a elevar o período de conservação das sementes e, ao mesmo tempo, que a redução do grau de umidade prolongou esse período, independentemente da temperatura de armazenamento.

Observando o andamento dos dados nos períodos de armazenamento, as sementes com $16 \% \mathrm{H}_{2} \mathrm{O}\left(\mathrm{a} 10^{\circ} \mathrm{C}\right.$ ) e com $10 \% \mathrm{H}_{2} \mathrm{O}$ (a $10^{\circ} \mathrm{C}$ e a $20^{\circ} \mathrm{C}$ ) foram apresentando tendência de superioridade, em relação aos demais tratamentos, evidenciada na última época de avaliação (48 semanas); contudo, nesta ocasião, mostraram taxas de germinação ainda superiores a $70 \%$ e não diferenciáveis estatisticamente entre si. Portanto, apesar de importante nas separações quantitativas observadas no conjunto dos tratamentos, o teste de germinação não conseguiu isolar, com precisão, a associação mais adequada entre o grau de umidade e a temperatura de armazenamento para a conservação das sementes. Esta falta de sensibilidade, para a detecção de reduzidas diferenças na qualidade fisiológica, tem sido prevista na literatura (Toledo \& Marcos Filho, 1977; Marcos Filho et al., 1987) e, talvez, pudesse ter sido controlada com a ampliação do período experimental. 


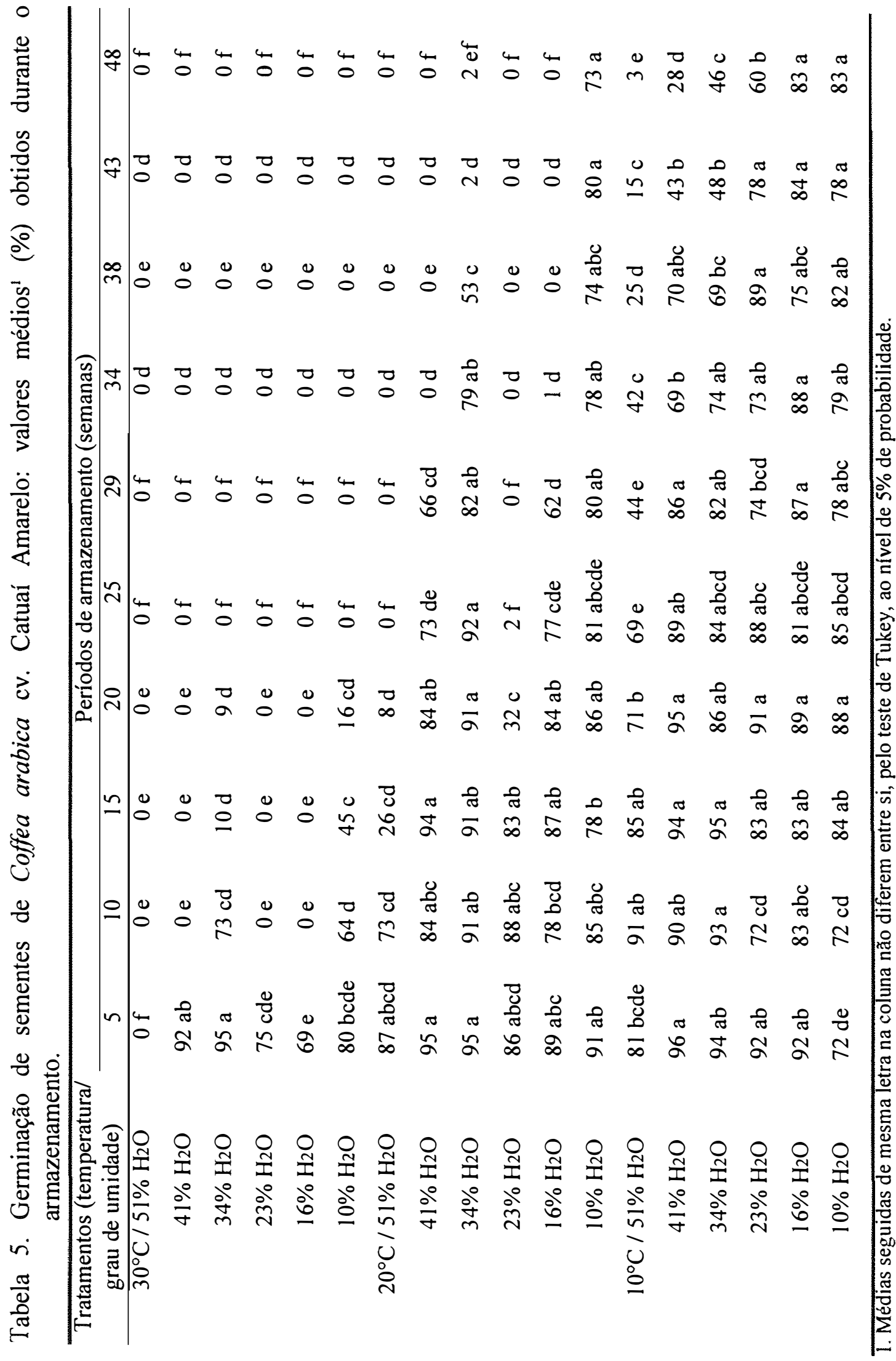




\subsection{Vigor das sementes durante 0 armazenamento}

Uma das manifestações finais da deterioração nas sementes é a perda da capacidade de germinação. Todavia, a redução do poder germinativo é, frequentemente, precedida ou acompanhada pela redução no desenvolvimento das plântulas, como consequência da perda das funções vitais que não ocorrem simultaneamente nos diferentes tecidos das sementes (Toledo \& Marcos Filho, 1977). Desse modo, os testes de vigor, baseados na avaliação das plântulas, podem complementar as informações obtidas no teste de germinação a respeito do processo de deterioração.

Por este motivo, no presente trabalho, o vigor das sementes foi estimado pelos testes de comprimento, de matéria seca, de velocidade de emergência e de emergência de plântulas (Tabelas 6, 7, 8, e 9). A interpretação dos dados, isoladamente para cada teste, não identificou, entre os testes, variações expressivas nas indicações fornecidas. Assim, os tratamentos puderam ser comparados segundo o desempenho predominante no conjunto das avaliações.

No ambiente a $30^{\circ} \mathrm{C}$, a redução do vigor ocorreu, principalmente nas sementes com 51, 41, 23 e $16 \% \mathrm{H}_{2} \mathrm{O}$, de modo acentuado; nas sementes com 34 e 10\% $\mathrm{H}_{2} \mathrm{O}$, essa diminuição quantitativa foi prorrogada, particularmente nas sementes com $10 \% \mathrm{H}_{2} \mathrm{O}$.

Sob temperatura de $20^{\circ} \mathrm{C}$, apesar de verificada a superioridade das sementes de $10 \% \mathrm{H}_{2} \mathrm{O}$ nas comparações com as dos demais graus de umidade, as sementes com 51, 41, 23 e $16 \% \mathrm{H}_{2} \mathrm{O}$ demonstraram desempenho inferior, ao longo do armazenamento, em relação às que se achavam com $34 \% \mathrm{H}_{2} \mathrm{O}$ que, segundo as observações de Ibrahim et al. (1983) e de Ellis et al. (1990), podem haver sido beneficiadas por balanço mais favorável entre as taxas de deterioração e de reparos celulares.

No ambiente a $10^{\circ} \mathrm{C}$, os dados indicaram que o decréscimo do grau de umidade favoreceu a manutenção do vigor das sementes. Assim, no final do período experimental, essa tendência foi evidenciada com a superioridade das sementes de $10 \%$ $\mathrm{H}_{2} \mathrm{O}$ em relação às dos demais graus de umidade, à exceção das sementes de $16 \% \mathrm{H}_{2} \mathrm{O}$. 
As sementes com $51 \% \mathrm{H}_{2} \mathrm{O}$ foram as primeiras, dentro de cada temperatura, a acentuar reduções no vigor. Com isso, foi relevada a importância da secagem, antes do armazenamento em embalagem impermeável ao vapor d'água (Miglioranza, 1982; Silva \& Dias, 1985), considerando que a manutenção do grau de umidade original, presente após a degomagem, foi prejudicial à conservação. Adicionalmente, entre as temperaturas, a de $10^{\circ} \mathrm{C}$ foi a que manteve a qualidade fisiológica dessas sementes por maior período de tempo, sugerindo a ocorrência de diminuição na velocidade de deterioração em relação à dos demais ambientes.

Os resultados obtidos nos testes de vigor, apresentando tendência geral similar à detectada na germinação, sugeriram que as reduções do grau de umidade e da temperatura de armazenamento conduziram à diminuição da intensidade da deterioração e, por conseguinte, ao aumento do período de conservação das sementes, concordando com o relatado por Roberts (1972), Popinigis (1977), Toledo \& Marcos Filho (1977), Carvalho \& Nakagawa (1988) e Copland \& McDonald (1995) em relação às sementes ortodoxas.

No decorrer do armazenamento, as sementes mantidas a $10^{\circ} \mathrm{C}$ com $16 \mathrm{e}$ $10 \% \mathrm{H}_{2} \mathrm{O}$ foram evidenciando tendência de superioridade no desempenho em relação às dos demais tratamentos; no entanto, ao final do período experimental, não foram verificadas diferenças estatísticas significativas entre ambas. Portanto, de modo similar ao constatado no teste de germinação, os testes de vigor não conseguiram isolar a associação mais adequada entre o grau de umidade e a temperatura de armazenamento para a conservação das sementes. Porém, confrontando os resultados obtidos com os verificados por Hong \& Ellis (1992), há indicações que o grau de umidade de $10 \%$ e a temperatura de $10^{\circ} \mathrm{C}$ sejam as condições mais adequadas, dentre as demais testadas, para a conservação das sementes de Coffea arabica. 


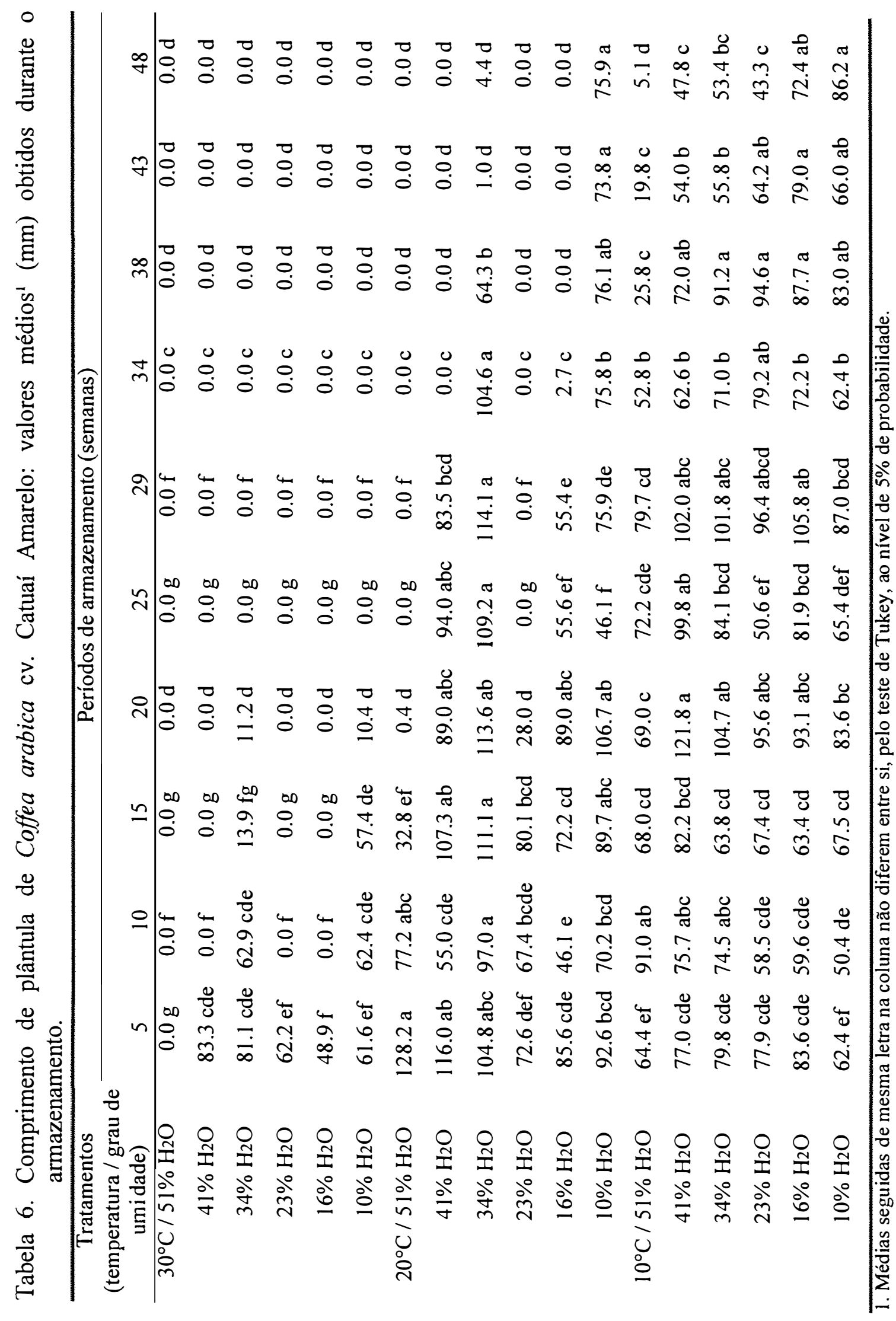




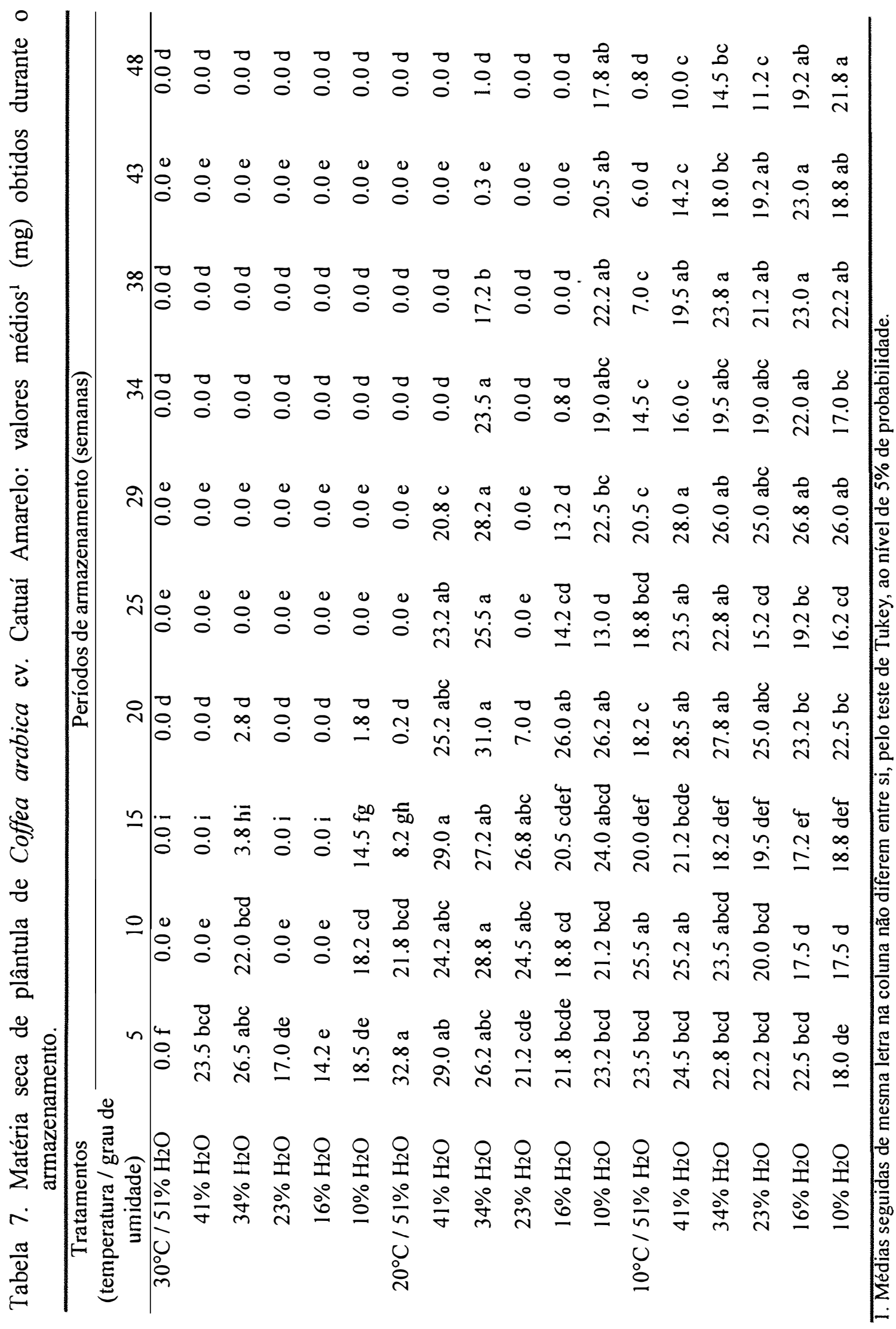




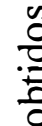

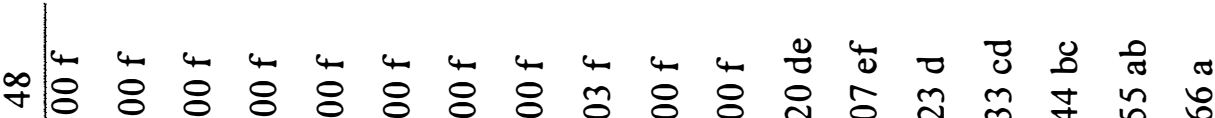
ฮั

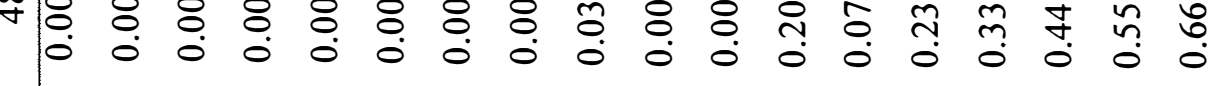

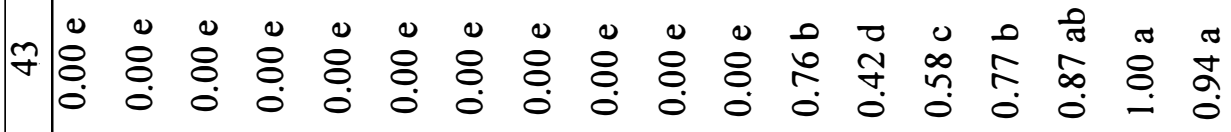

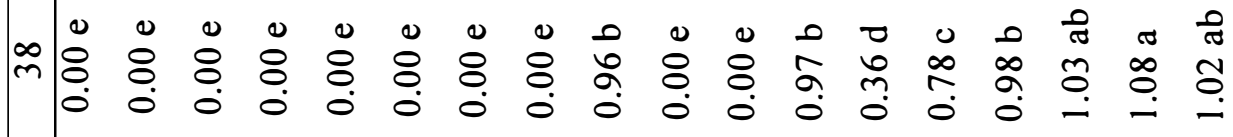

을

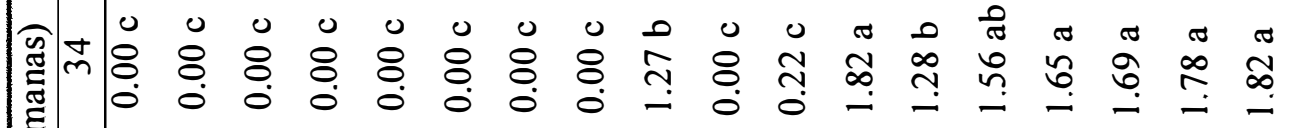

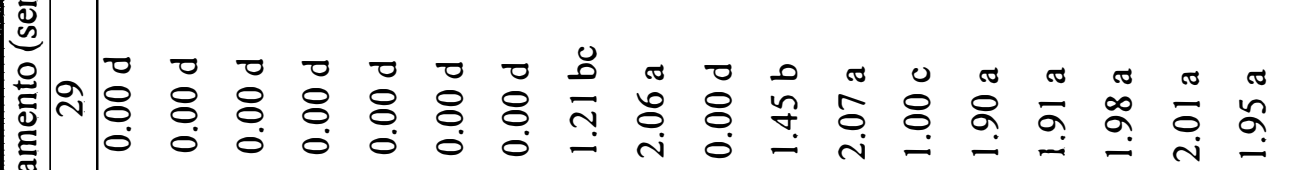

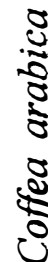

ช

奈

$\stackrel{\text { : }}{\mathbf{E}}$

\&)

超

$\approx$ N

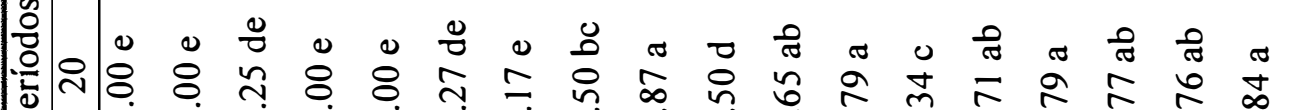

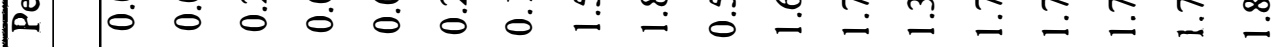

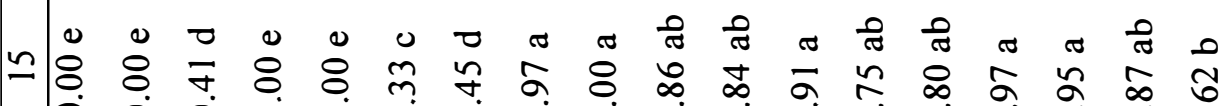
-

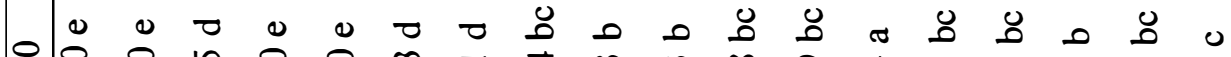

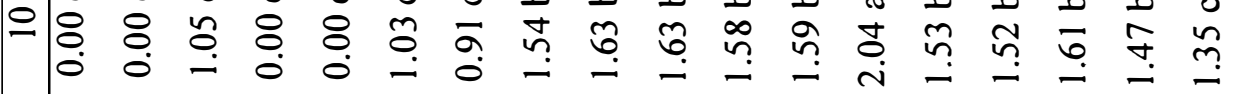

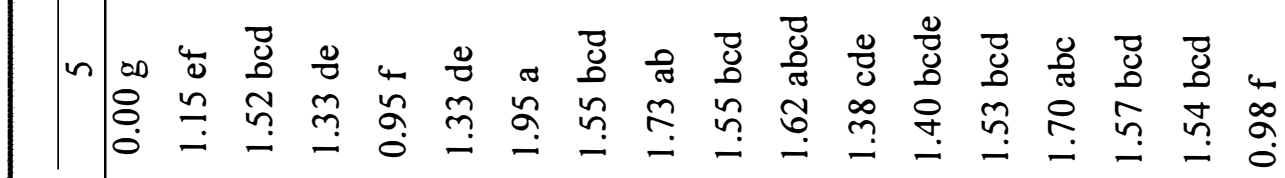

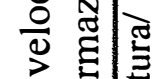

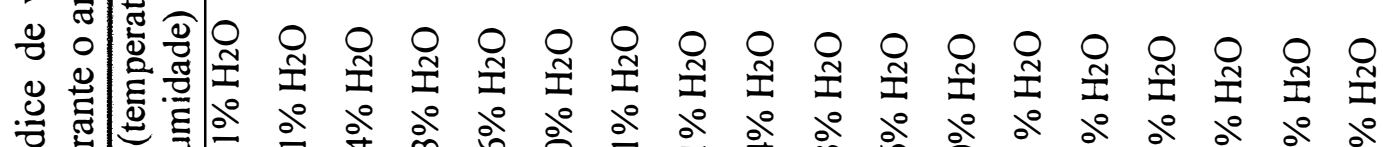

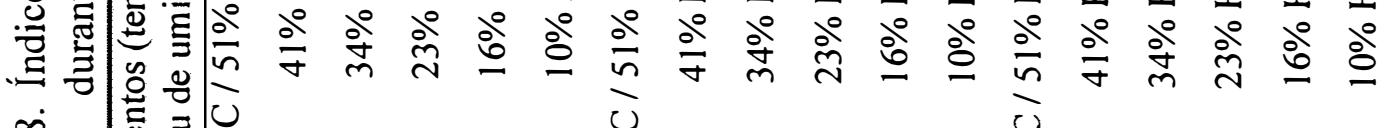

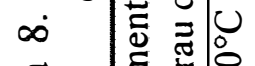

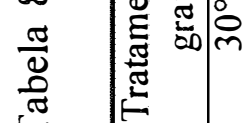

نे

U 


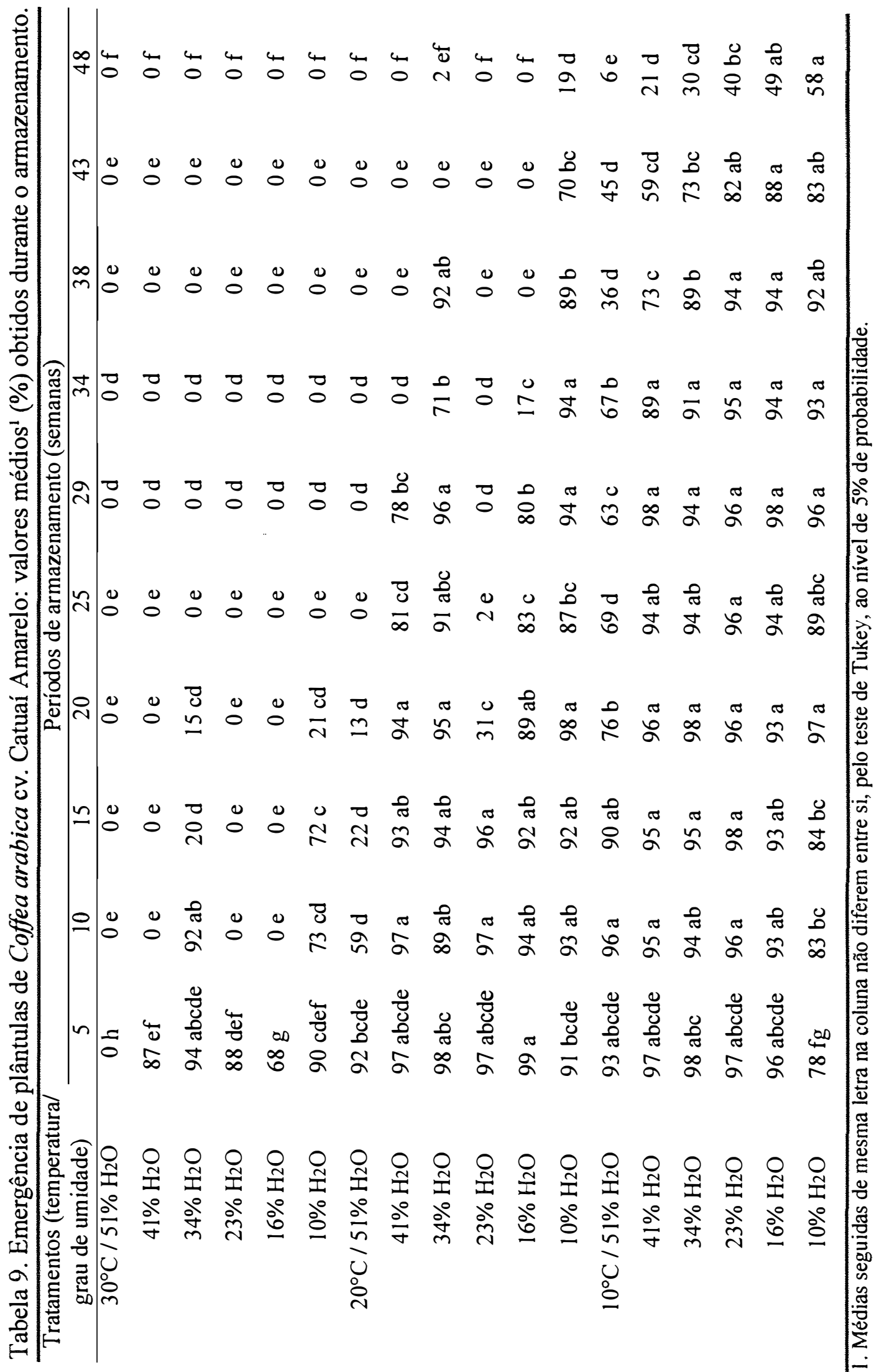




\subsection{Sanidade das sementes durante 0 armazenamento}

A análise de sanidade visou avaliar o andamento da incidência dos fungos Penicillium sp. e Aspergillus sp. e verificar sua eventual relação com a qualidade fisiológica das sementes armazenadas, considerando que a atividade de microrganismos, além de poder causar reduções na viabilidade e no vigor da semente, pode promover a morte do embrião (Christensen, 1972; Roberts, 1972; Popinigis, 1977; Carvalho \& Nakagawa, 1988; Copeland \& McDonald, 1995).

Os dados de incidência de Penicillium sp. (Tabela 10) sugeriram, particularmente no ambiente a $10^{\circ} \mathrm{C}$, a associação positiva entre a elevação da ocorrência do microrganismo e a ampliação do período de armazenamento nas sementes com $23 \% \mathrm{H}_{2} \mathrm{O}$. Entre os demais graus de umidade, apesar da incidência esporádica e sem apresentar tendências evidentes relacionadas ao prazo de armazenamento, os resultados indicaram o de $34 \% \mathrm{H}_{2} \mathrm{O}$ como favorável ao estabelecimento do fungo, independentemente da temperatura considerada.

Em relação a Aspergillus sp. (Tabela 11), a incidência ocorreu em intensidade menor do que a verificada em Penicillium sp. e, paralelamente, sem evidenciar tendências de elevação da ocorrência do fungo durante o armazenamento. Contudo, nas comparações entre os diferentes graus de umidade, a incidência foi maior e mais frequente nas sementes com $34 \%$ e, principalmente, $23 \% \mathrm{H}_{2} \mathrm{O}$, independentemente da temperatura de armazenamento.

Dessa maneira, as presenças de Penicillium sp. e de Aspergillus sp., efetivamente detectadas nas sementes com 23 e $34 \% \mathrm{H}_{2} \mathrm{O}$, foram mais expressivas naquelas com $23 \% \mathrm{H}_{2} \mathrm{O}$ (Tabelas 10 e 11). Além disso, fixados os períodos de armazenamento e os graus de umidade, a redução da temperatura tendeu a diminuir a incidência desses microrganismos.

$\mathrm{O}$ grau de umidade e a temperatura são fatores que interferem no desenvolvimento de fungos em sementes armazenadas (Christensen, 1972). Em sementes com graus de umidade de valores reduzidos, próximos ao do limite mínimo para o estabelecimento dos fungos (12 a $\left.19 \% \mathrm{H}_{2} \mathrm{O}\right)$, o ataque é lento; à medida que o 
grau de umidade se eleva, o estabelecimento dos fungos é acelerado e, consequentemente, maiores são as possibilidades do surgimento de prejuízos à qualidade fisiológica das sementes (Harrington, 1972; Popinigis, 1977). Da mesma forma, existem temperaturas mínimas, ótimas e máximas que determinam o desenvolvimento das várias espécies de Penicillium e de Aspergillus nas sementes armazenadas (Christensen, 1972).

Muito embora a incidência de fungos de armazenamento tenha sido mais elevada nas sementes com $23 \% \mathrm{H}_{2} \mathrm{O}$, não foi possível estabelecer relações precisas de sua interferência sobre a qualidade fisiológica. Resultados obtidos por Miranda (1987) evidenciaram, de maneira aproximada, maior ocorrência desses microrganismos em sementes com grau de umidade de $22 \%$, armazenadas em ambiente sem o controle da temperatura. Assim, é provável que em torno desse valor a umidade seja favorável à incidência de Penicillium sp. e de Aspergillus sp. em sementes de Coffea arabica.

\subsection{Considerações adicionais}

A secagem realizada nas sementes, necessária à obtenção dos diferentes graus de umidade, gerou variabilidade qualitativa que, particularmente, evidenciou maiores prejuízos fisiológicos às sementes que atingiram $10 \% \mathrm{H}_{2} \mathrm{O}$. Contudo, apesar de desfavorecidas na qualidade inicial, as sementes com $10 \% \mathrm{H}_{2} \mathrm{O}$ foram as que apresentaram menor deterioração ao serem considerados os desempenhos no conjunto das temperaturas de armazenamento. Assim, ficou destacada a importância da diferenciação entre os efeitos decorrentes da desidratação e os da conservação em pesquisas com sementes de Coffea arabica.

Paralelamente, embora não fazendo parte integrante do objetivo do trabalho, foi verificada, em algumas ocasiões, a superioridade dos dados de emergência em relação aos de germinação. Este fato, apesar de discordante do relatado pela literatura (Delouche, 1973), forneceu indicações de que as condições, adotadas para a realização do teste de germinação, podem levar a uma interpretação distorcida do desempenho potencial das sementes analisadas; por conseguinte, o aprimoramento dos 
métodos de avaliação da qualidade fisiológica, das sementes dessa espécie, merece atenção. 


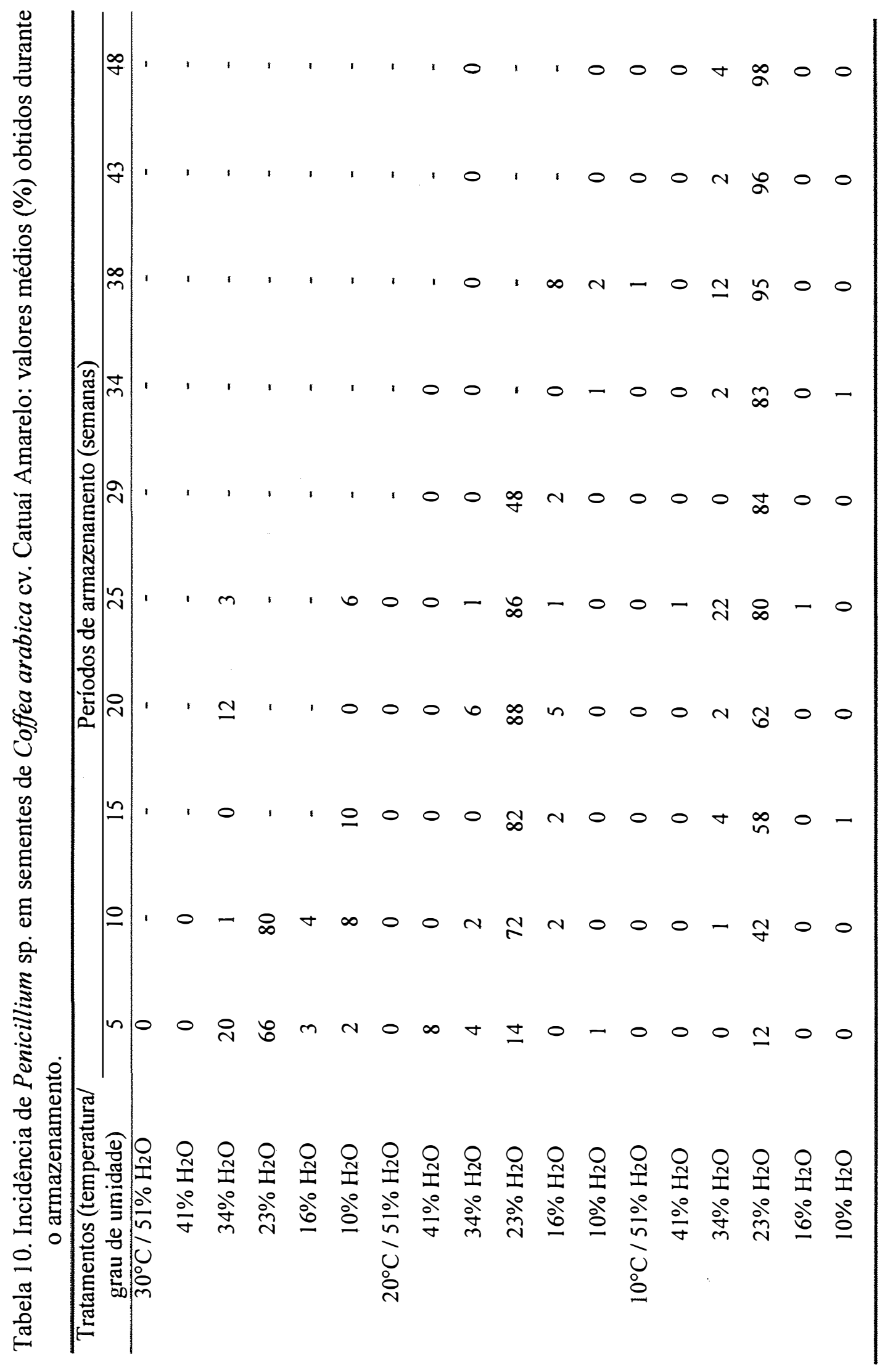




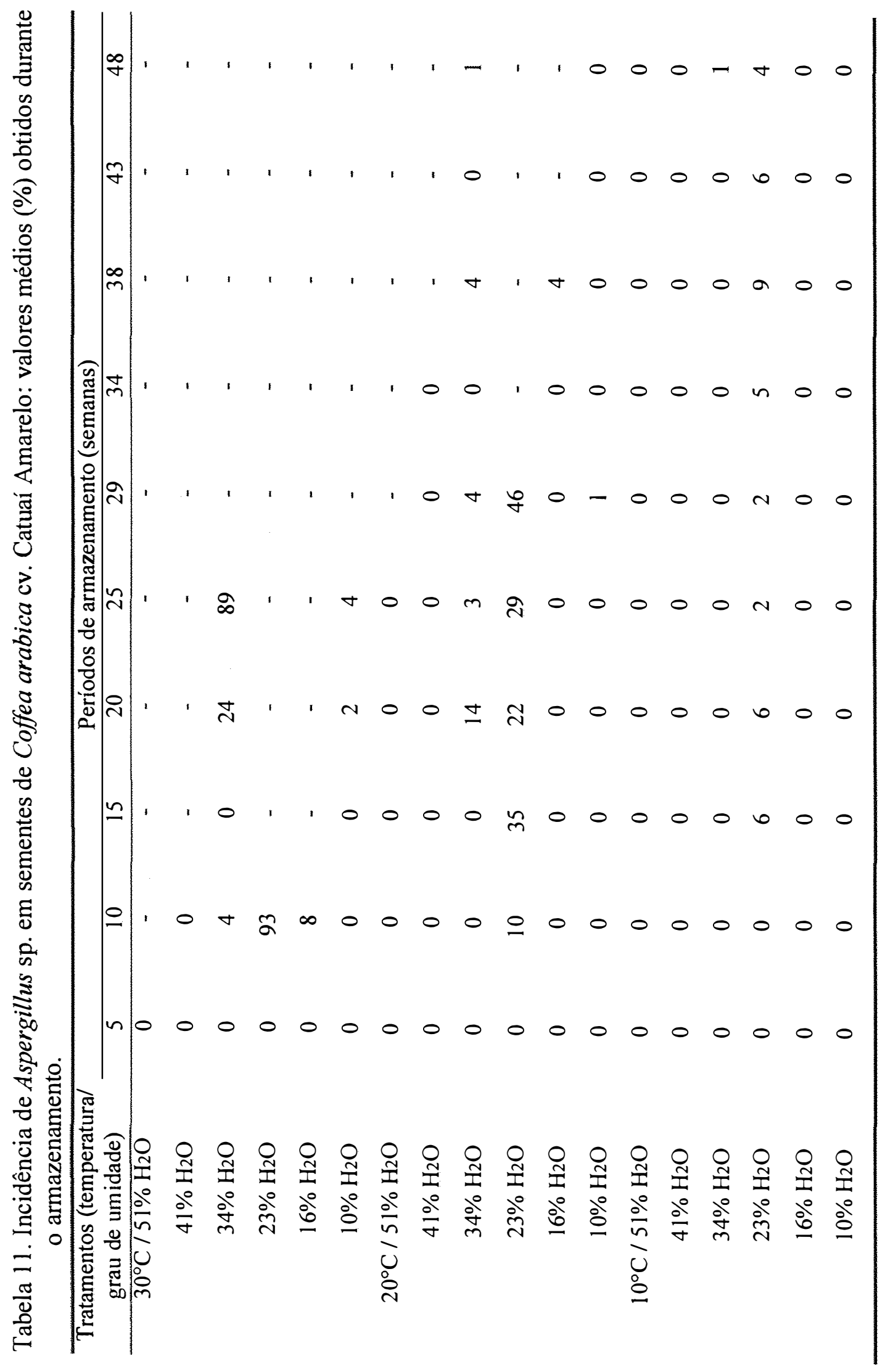




\section{CONCLUSÕES}

Considerado o armazenamento de sementes de Coffea arabica com 10 a $51 \% \mathrm{H}_{2} \mathrm{O}$ em ambientes de $10^{\circ} \mathrm{C}$ a $30^{\circ} \mathrm{C}$, pode ser concluído que:

- as reduções do grau de umidade e da temperatura são favoráveis à manutenção da qualidade fisiológica das sementes;

- umidades próximas de $23 \%$ beneficiam o estabelecimento de Penicillium sp. e de Aspergillus sp. nas sementes. 


\section{REFERÊNCIAS BIBLIOGRÁFICAS}

AGUILERA, V.H.; GOLDBACH, H. Storage of coffee (Coffea arabica L.) seed. Journal of Seed Technology, v.5, n.2, p.7-13, 1980.

ALIZAGA, R.; HERRERA, J. Desarrollo del fruto y de la semilla en dos cultivares de café (Coffea arabica) y su relacion con la germinación y el almacenamiento. Agronomía Costarricense, v.19, n.1, p.61-61, 1995.

ARAÚJO, R.P. Influência do teor de umidade, da embalagem e do ambiente de armazenamento na conservação de sementes de café (Coffea arabica L.). Viçosa, 1988. 56 p. Dissertação (Mestrado) - Universidade Federal de Viçosa.

ARAÚJO, E.F.; CORRÊA, P.C.; PEREIRA, O.A. Influência da temperatura de secagem na germinação de sementes de café. Revista Brasileira de Sementes, v.11, n.1-3, p.69-75, 1989.

ARCILA-PULGARÍN, J. Influencia de la temperatura de secado en la germinacion de las semillas de cafe. Cenicafé, v.27, n.2, p.89-91, 1976.

ASCANIO E., C.E. Biologia del cafe. Caracas: Universidad Central de Venezuela, 1994. 308p.

ASTOLFI, P.T.; PEDROSO, P.A.C.; CARVALHO, N.M.; SADER, R. Maturação de sementes de café (Coffea arabica L. cv. Mundo Novo). Científica, v.9, n.2, p.289294, 1981.

AUSTIN, R.B. Effects of environment before harvesting on viability. In: ROBERTS, E.H. (Ed.) Viability of seeds. Syracuse: Syracuse University Press, 1972. cap.5, p.114-149.

BACCHI, O. Seca da semente de café ao sol. Bragantia, v.14, n.22, p.225-236, 1955.

BACCHI, O. Novos ensaios sobre a seca da semente de café ao sol. Bragantia, v.15, n.8, p.83-91, 1956. 
BACCHI, O. Estudo sobre conservação de sementes. IV - Café. Bragantia, v.17, n.20, p.261-270, 1958.

BARBOZA, R.; HERRERA, J. El vigor en la semilla de cafe y su relacion con la temperatura de secado, el contenido de humedad y las condiciones de almacenamiento. Agronomía Costarricense, v.14, n.1, p.1-7, 1990.

BENDAÑA, F.E. Fisiologia de las semillas de cafe. I. Problemas relativos al almacenamiento. Cafe, v.4, n.15, p.93-96, 1962.

BOUHARMONT, P. La conservation des graines de caféier destinées a la multiplication au Cameroun. Café Cacao Thé, v.15, n.3, p.202-210, 1971.

BRASIL. Ministério da Agricultura e Reforma Agrária. Regras para análise de sementes. Brasília: CLAV/DNDV/SNAD/MA, 1992. 365p.

BRICKWOOD, A.W. Algumas observações sobre a cultura do café. Hacienda, v.9, p.259-264, 1914.

CAIXETA, I.F. Maturação fisiológica da semente de cafeeiro (Coffea arabica L.) cv. Mundo Novo. Lavras, 1981. 48p. Dissertação (Mestrado) - Escola Superior de Agricultura de Lavras.

CAMARGO, R.; TELlES JÚNIOR, A.Q. O café no Brasil: sua aclimatação e industrialização. v.1. Rio de Janeiro: Ministério da Agricultura, 1953. 535p. (Série Estudos Brasileiros, 4).

CARVALHO, M. M. Formação de mudas. Informe Agropecuário, v.4, n.44, p.14-18, 1978.

CARVALHO, N.M.; NAKAGAWA, J. Sementes: ciência, tecnologia e produção. 3.ed. Campinas: Fundação Cargill, 1988. 424p.

CASTRO, F.S. Escogencia y tratamiento de la semilla de café. Agricultura Tropical, v.16, n.11, p.715-724, 1960.

CHIN, H.F. Seed production and processing. In: CHIN, H. F.; ROBERTS, E.H. Recalcitrant crop seeds. Kuala Lumpur: Tropical Press, 1980. cap.6, p. 111-133.

CHRISTENSEN, C.M. Microflora and seed deterioration. In: ROBERTS, E.H. (Ed.)

Viability of seeds. Syracuse: Syracuse University Press, 1972. cap.3, p.59-93. 
COPELAND, L.O., McDONALD, M.B. Principles of seed science and technology. 3.ed. New York: Chapman \& Hall, 1995. 409p.

COSTA, J.D. Produção de café. Piracicaba: ESALQ/USP - SEBRAE/SP, 1994. 21 p. (Cursos Agrozootécnicos).

COSTÉ, R. Le caféier. Paris: G. P. Maisonneuve \& Larose, 1968. 310p. (Techniques Agricoles et Productions Tropicales, 14).

COUTURON, E. Le maintien de la viabilité des graines de caféiers par le contrôle de leur teneur en eau et de la température de stockage. Café Cacao Thé, v.24, n.1, p.2732, 1980.

CROMARTY, A.S.; ELLIS, R.H.; ROBERTS, E.H. Desing of seed storage facilities for genetic conservation. Rome: IBPGR, 1985. 100p.

DELOUCHE, J.C. Physiology of seed storage. In: CORN AND SORGHUM RESEARCH CONFERENCE, 23., 1968. Proceedings. Washington: ASTA, 1968. p.83-90.

DELOUCHE, J.C. Seed vigour in soybeans. In: SOYBEAN SEED RESEARCH CONFERENCE, 3., 1973. Proceeding. Washington: ASTA, 1973. p.56-72.

DIAS, M.C.L.L.; BARROS, A.S.R. Avaliação de métodos para a remoção da mucilagem de sementes de café (Coffea arabica L.). Revista Brasileira de Sementes, v.15, n.2, p.191-195, 1993a.

DIAS, M.C.L.L.; BARROS, A.S.R. Conservação de sementes de café (Coffea arabica L.) em diferentes embalagens. Revista Brasileira de Sementes, v.15, n.2, p.197$202,1993 b$.

DUSSERT, S.; CHABRILLANGE, N.; ENGELMANN, F.; HAMON, S. Quantitative estimation of seed desiccation sensitivity using a quantal response model: application to nine species of the genus Coffea L. Seed Science Research, v.9, n.2, p.135-144, 1999.

ELLIS, R.H.; HONG, T.D.; ROBERTS, E.H. An intermediate category of seed storage behaviour? I. Coffee. Journal of Experimental Botany, v.41, n.230, p.1167-1174, 1990. 
ELLIS, R.H.; HONG, T.D.; ROBERTS, E.H. An intermediate category of seed storage behaviour? II. Effects of provenance, immaturity, and imbibition on desiccationtolerance in coffee. Journal of Experimental Botany, v.42, n.238, p.653-657, 1991.

FAO. Food and Agriculture Organization of the United Nations. Production yearbook. v.51. Rome: 1997. p.174. (Fao Statistics Series, 142).

FARRANT, J.M.; PAMMENTER, N.W.; BERJAK, P. Recalcitrance - a current assessment. Seed Science and Technology, v.16, p.155-166, 1988.

FERREIRA, P.V. Estatística experimental aplicada à agronomia. Maceió: EDUFAL, 1991. 437p.

FILANI, G.A. Chemical treatment of coffee seeds in relation to germination, emergence and control of seed-borne fungi. Turrialba, v.22, n.1, p.40-46, 1972.

HAARER, A.E. Modern coffee production. London: Leonard Hill (Books) Limited, 1962. 495p.

HARRINGTON, J.F. Seed storage and longevity. In: KOZLOWSKI, T.T. (Ed.) Seed biology: insects, and seed collection, storage, testing, and certification. v.3. New York: Academic Press, 1972. cap.3, p.145-245. (Physiological ecology: a series of monographs, texts, and treatises).

HERNANDEZ, H.P. O cultivo do café em Venezuela. Hacienda, v.5, p.24-27, 1909.

HERRERA, J.; ALIZAGA, R.; ALIZAGA, G. Efecto de la madurez del fruto de café (Coffea arabica) cv. Caturra sobre la germinación y el vigor de las semillas. Agronomía Costarricense, v.17, n.1, p.25-32, 1993.

HONG, T.D.; ELLIS, R.H. Optimum air-dry seed storage environments for arabica coffee. Seed Science and Technology, v.20, p.547-560, 1992.

HONG, T.D.; ELLIS, R.H. A protocol to determine seed storage behaviour. In: ENGELS, J. M. M.; TOLL, J. (Ed.) IPGRI Technical Bulletin n. 1. Rome: IPGRI, 1996. 62p.

IBRAHIM, A.E.; ROBERTS, E.H. Viability of lettuce seeds. I. Survival in hermetic storage. Journal of Experimental Botany, v.34, n.142, p.620-630, 1983. 
IBRAHIM, A.E.; ROBERTS, E.H.; MURDOCH, A.J. Viability of lettuce seeds. II. Survival and oxygen uptake in osmotically controlled storage. Journal of Experimental Botany, v.34, n.142, p.631-640, 1983.

ICEA. Instituto Campineiro de Ensino Agrícola. Cultura de café. Campinas: 1987. $84 \mathrm{p}$.

KING, M.W.; ROBERTS, E.H. The storage of recalcitrant seeds: achievements and possible approaches. Rome: IBPGR, 1979. 96p.

KING, M.W.; ROBERTS, E.H. Maintenance of recalcitrant seeds in storage. In: CHIN, H. F.; ROBERTS, E.H. Recalcitrant crop seeds. Kuala Lumpur: Tropical Press, 1980. cap.4, p.53-89.

KOUTAKA, S. Recomendações práticas para viveiros de cafeeiros. Brasil Oeste, v.11, n.118, p.9, 1966.

MACEDO, J.C.C. Preparação da semente de café por fermentação e por exposição ao sol. Revista do Café Português, v.4, n.13, p.34-46, 1957.

MAGUIRE, J.D. Speed of germination: aid in selection and evaluation for seedling emergence and vigour. Crop Science, v.2, n.2, p.176-177, 1962.

MARCOS FILHO, J.; CÍCERO, S.M.; SILVA, W.R. Avaliação da qualidade fisiológica das sementes. Piracicaba: FEALQ, 1987. 230p.

MASFERRÉ, J.O. O cultivo do café em Filipinas. Hacienda, v.5, p. 268-271, 1910.

MATIELlO, J. B. O café: do cultivo ao consumo. São Paulo: Globo, 1991. 320p. (Coleção do Agricultor. Grãos. Publicações Globo Rural).

McCLELLAND, T.B. Indicações sobre a plantação do café. Hacienda, v.17, p.306310, 1922.

MEDINA, J.A.; MOROCOIMA, J.M.; ROMAN, N.; MESA, P.A. Producción de semilla selecta de café. Fonaiap Divulga, v.1, n.4, p.37, 1982.

MIGLIORANZA, E. Conservação de sementes de café (Coffea arabica L. cv. Catuaí) com diferentes teores de umidade, armazenadas em embalagens hermeticamente fechadas. Piracicaba, 1982. 60p. Dissertação (Mestrado) - Escola Superior de Agricultura "Luiz de Queiroz", Universidade de São Paulo. 
MIRANDA, J.M. Estudo de alguns fatores que influenciam a duração da viabilidade de sementes de café (Coffea arabica L. cv. Catuaí). Lavras, 1987. 60 p. Dissertação (Mestrado) - Escola Superior de Agricultura de Lavras.

MIRANDA, J.M.; VALIAS, E.P.; SILVA, R.F. Estudo sobre a conservação da viabilidade de sementes de café. In: CONGRESSO BRASILEIRO DE PESQUISAS CAFEEIRAS, 11., Londrina, 1984. Anais. Rio de Janeiro: IBC, 1984. p. 160-162.

MOORE, R.P. Effects of mechanical injuries on viability. In: ROBERTS, E.H. (Ed.)

Viability of seeds. Syracuse: Syracuse University Press, 1972. cap.4, p.94-113.

MORAES, F.R.P. Meio ambiente e práticas culturais. In: INSTITUTO Brasileiro de Potassa (Ed.) Cultura e adubação do cafeeiro. São Paulo: 1963. p.77-126.

ORTUÑO V., F.; ECHANDI Z., R. Efecto de condiciones de almacenamiento sobre la viabilidad y vigor de la semilla de cafe (Coffea arabica L.). Agronomia Costarricense, v.4, n.2, p.149-154, 1980.

POPINIGIS, F. Fisiologia de sementes. Brasília: AGIPLAN, 1977. 289p.

PRADO FILHO, H.P.A.; KAISER, A.A.P.G.; DIAS, M.C.L.L. Comparação de métodos para degomagem no processo de produção de sementes de café. In: CONGRESSO BRASILEIRO DE PRODUÇÃP CAFEEIRA, 11., Londrina, 1984. Resumos. Rio de Janeiro: MIC/IBC, 1984. p.79-80.

PROBERT, R.; SMITH, R. Seed viability and the prediction of longevity. /Apresentado ao Seed Conservation Training Course, UNESP, Jaboticabal/SP, 1996/ RENA, A.B.; MAESTRI, M. Fisiologia do cafeeiro. In: RENA, A.B.; MALAVOLTA, E.; ROCHA, M.; YAMADA, T. (Ed.) Cultura do cafeeiro: fatores que afetam a produtividade. Piracicaba: ABPPF, 1986. p.13-85.

RIOS, P.G. La germinación de la semilla de café. Revista de Agricultura de Puerto Rico, v.22, n.10, p.147-148, 1929.

ROBERTS, E.H. Storage environment and the control of viability. In: ROBERTS, E.H. (Ed.) Viability of seeds. Syracuse: Syracuse University Press, 1972. cap.2, p.14-58. ROBERTS, E.H. Predicting the storage life of seeds. Seed Science and Technology, v.1, p.499-514, 1973. 
ROBERTS, E.H.; ELLIS, R.H. Water and seed survival. Annals of Botany, v.63, n.1, p.39-52, 1989.

ROBERTS, E.H.; KING, M.W. The characteristics of recalcitrant seeds. In: CHIN, H. F.; ROBERTS, E.H. Recalcitrant crop seeds. Kuala Lumpur: Tropical Press, 1980. cap.1, p.1-5.

RODRÍGUEZ, S.J. Semilleros y viveros de cafe. Revista Agricola de Puerto Rico, v.44, n.2, p.98-102, 1965.

ROMERO, F.B. Semillas: biologia y tecnologia. Madrid: Mundi-Prensa, 1989. 637p.

SCARANARI, H.J. Instalação do cafezal. In: GRANER, E. A.; GODOY JÚNIOR, C.

(Coord.) Manual do cafeicultor. São Paulo: Melhoramentos, 1967. p.105-125.

SILVA, W.R.; DIAS, M.C.L.L. Interferência do teor de umidade das sementes de café na manutenção de sua qualidade fisiológica. Pesquisa Agropecuária Brasileira, v.20, n.5, p.551-560, 1985.

SOTO, F.; ECHEVARRÍA, I.; RODRÍGUEZ, P. Estudio sobre la conservacion de semillas de cafetos (Coffea arabica $\mathrm{L}$. variedad Caturra). Cultivos Tropicales, v.16, n.1, p.33-36, 1995.

STORING coffee seed. Bergcultures, v.13, p.1506-1512, 1939. /Resumo em Tropical Agriculture, v.18, n.2, p.25, 1941/

TOLEDO, F.F.; MARCOS FILHO, J.M. Manual de sementes: tecnologia da produção. São Paulo: Agronômica Ceres, 1977. 224p.

THORN, J. O guia do café: guia dos conhecedores das melhores infusões do mundo. Trad. de L. Geer. China: Livros e Livros, 1998. 192p.

VALIO, I.F.M. Germination of coffee seeds (Coffea arabica L. cv. Mundo Novo). Journal of Experimental Botany, v.27, n.100, p.983-991, 1976.

VASCONCELOS, L.M.; GROTH, D.; RAZERA, L.F. Efeito de processos de secagem, diferentes graus de umidade e tipos de embalagens na conservação de sementes de café (Coffea arabica L. cv. Catuaí Vermelho). Revista Brasileira de Sementes, v.14, n.2, p.181-188, 1992.

VEGRO, C.L.R.; MORICOCHI, L.; JOHNSON, B. Café: realidade e perspectivas. São Paulo: SAA, 1997. 79p. (Coleção Cadeias de Produção da Agricultura, 2). 
VILLIERS, T.A.; EDGCUMBE, D.J. On the cause of seed deterioration in dry storage. Seed Science \& Technology, v.3, n.3-4, p.761-774, 1975.

VOSSEN, H.A.M. Methods of preserving the viability of coffee seed in storage. Seed Science \& Technology, v.7, p.65-74, 1979.

VOSSEN, H.A.M. Coffee selection and breeding. In: CLIFFORD, M.N.; WILLSON, K.C. (Ed.) Coffee: botany, biochemistry, and production of beans and beverage. Sidney: Croom Helm, 1985. p.48-96.

ZONTA, E.P.; MACHADO, A.A. Programa SANEST: sistema de análise estatística para microcomputadores (software). Pelotas: UFPel, 1984. (Disquete). 